\title{
Identificação e análise de áreas suscetíveis a fluxos de detritos na bacia hidrográfica do Rio Taquari-Antas, RS
}

\author{
Guilherme Garcia de OLIVEIRA ${ }^{1}$, Laurindo Antonio GUASSELLI ${ }^{2}$, Renata Pacheco QUEVEDO², \\ Luis Fernando Chimelo RUIZ², Luiz Antônio BRESSANI ${ }^{3}$ \& Eduardo Samuel RIFFEL ${ }^{2}$ \\ ${ }^{1}$ Departamento Interdisciplinar, Campus Litoral Norte, Universidade Federal do Rio Grande do Sul. Rodovia RS 030, 11.700, km \\ 92, CEP 95590-000, Tramandaí, RS, Brasil (g.g.oliveira10@gmail.com). \\ 2 Programa de Pós-graduação em Sensoriamento Remoto, Universidade Federal do Rio Grande do Sul. Av. Bento Gonçalves, \\ 9.500, CEP 91540-000, Porto Alegre, RS, Brasil (laurindo.guasselli@ufrgs.br, ruiz.ch@gmail.com, edriffel@gmail.com). \\ ${ }^{3}$ Programa de Pós-graduação em Engenharia Civil, Universidade Federal do Rio Grande do Sul. Av. Osvaldo Aranha, 99 (3o \\ Andar), CEP 90035-190, Porto Alegre, RS, Brasil (bressani@ufrgs.br).
}

Oliveira, G.G, Guasselli, L.A., Quevedo, R.P., Ruiz, L.F.C., Bressani, L.A., Riffel, E.S. 2018. Identificação e análise de áres suscetíveis a fluxos de detritos na bacia hidrográfica do Rio Taquari-Antas, RS. Pesquisas em Geociências, 45: e0732.

DOI: https://doi.org/10.22456/1807-9806.88685

\begin{abstract}
Resumo. 0 objetivo deste trabalho foi identificar e analisar as áreas suscetíveis a fluxos de detritos na bacia do Rio Taquari-Antas, RS. 0 mapeamento das áreas suscetíveis foi realizado por meio de uma modelagem espacial com abordagem probabilística, envolvendo a análise morfométrica em locais com ocorrência de fluxos de detritos. Os locais foram inventariados por meio de imagens orbitais e expedições em campo, tendo sido mapeadas 193 cicatrizes. A maior parte das cicatrizes se refere ao evento ocorrido em janeiro de 2010, na sub-bacia do rio Forqueta. A partir de alguns testes, foram definidos três atributos morfométricos para a modelagem: (i) declividades filtradas pela média em janela $5 \times 5$; (ii) desnível altimétrico das rampas; (iii) desnível altimétrico dos morros. Estes atributos apresentaram uma tendência central bem definida, com baixa dispersão dos dados e uma baixa correlação entre si. As cicatrizes mapeadas de deslizamentos apresentam uma área total de 27,3 ha, a maioria delas com comprimento superior a $150 \mathrm{~m}$ e largura na ordem de $10 \mathrm{~m}$. 0 desnível altimétrico médio dos morros com ocorrência de movimentos de massa foi de $317 \mathrm{~m}$, com declividade média de $39 \%$. Os resultados indicam que as áreas suscetíveis a fluxos de detritos, $8.147 \mathrm{~km}^{2}$ (30\% da bacia), estão localizadas principalmente ao longo das linhas de escarpa erosiva, no contato entre a Serra Geral e as unidades geomorfológicas adjacentes. As linhas de escarpa erosiva estão localizadas nas vertentes dos vales dos rios das Antas, da Prata, São Marcos, Carreiro, Guaporé, Forqueta, Fão e Taquari. Em termos absolutos, os municípios com maior área suscetível são Bom Jesus, Jaquirana e Fontoura Xavier. Cerca de 40 municípios apresentam mais de $50 \%$ de suas áreas como suscetíveis a fluxos de detritos.
\end{abstract}

Palavras-chave. Desastres naturais, movimentos de massa, geoprocessamento, índices morfométricos.

Abstract. IDENTIFICATION AND ANALYSIS OF SUSCEPTIBLE AREAS TO DEBRIS FLOW IN THE TAQUARI-ANTAS RIVER BASIN, RS. The aim of this paper was to identify and analyze the susceptible areas to debris flow in the Taquari-Antas River basin. We developed a spatial modeling with probabilistic approach involving the morphometric analysis in areas with occurrence of debris flow for the mapping of susceptible areas. The sites were inventoried from satellite images and on-site expeditions, have been mapped 193 scars. Most scars refer to the event occurred in January 2010, in the Forqueta river basin. We defined three morphometric attributes for modeling: (i) the average slope filtered in $5 \times 5$ window; (ii) altimetry slope of the ramp; (iii) altimetry slope of the hill. These attributes showed a well-defined central tendency, low data dispersion and low correlation with each other. The mapped scars of landslides have a total area of $27.3 \mathrm{ha}$, most of them with a length of more than $150 \mathrm{~m}$ and a width of around $10 \mathrm{~m}$. The average altimetric slope of the hills with mass movements was $317 \mathrm{~m}$, with a mean slope of $39 \%$. The results indicate that the susceptible areas to debris flow, $8.147 \mathrm{~km}^{2}$ (30\% of the basin), principally are located along the erosive escarpment lines, in contact between the Serra Geral and the adjacent geomorphological units. The lines of escarpment erosive are located on the slopes of the das Antas, da Prata, São Marcos, Carreiro, Guaporé, Forqueta, Fão and Taquari river valleys. In absolute terms, the municipalities with most susceptible areas that are Bom Jesus, Jaquirana and Fontoura Xavier. About 40 municipalities present more than $50 \%$ of their areas as susceptible to debris flows.

Keywords. Natural disasters, landslide, geoprocessing, morphometric indices 


\section{Introdução}

0 termo desastre é definido pela UNISDR (2009) como o resultado de eventos extremos, naturais ou provocados pelo homem, sobre uma área ocupada, na qual causam danos humanos, materiais e ambientais e consequentes prejuízos econômicos e sociais. No Brasil, os desastres naturais predominantes apresentam origem em eventos extremos hidrometeorológicos, sendo que a precipitação é o elemento atmosférico que mais contribui para a ocorrência de desastres na Região Sul (CEPED, 2013; Riffel et al., 2016). Entre as consequências mais drásticas da ocorrência de precipitações intensas sobre essa região estão as inundações, as enxurradas e os movimentos de massa, que ainda podem ser agravadas por ventos fortes e granizo, entre outros (Teixeira \& Satyamurty, 2004).

Dentre os desastres naturais que ocorrem no Brasil, as inundações, as enxurradas e os movimentos de massa são os que ocorrem com maior frequência e causam os maiores prejuízos. Estes eventos correspondem a $73 \%$ das ocorrências e $82 \%$ dos óbitos em função de desastres naturais no Brasil, entre 1900 e 2006 (Marcelino, 2008).

Uma vez que existem diferentes tipos de movimentos de massa, a identificação ou categorização do evento se constitui muitas vezes em uma tarefa complicada. Em alguns casos os eventos de movimentos de massa se confundem, dificultando ainda mais o entendimento dos mecanismos que influenciam na sua deflagração e deslocamento. Os deslizamentos e os fluxos de detritos, por exemplo, muitas vezes se encontram associados, pois o início do fluxo está normalmente vinculado à ocorrência de um conjunto de deslizamentos (Guidicini \& Nieble, 1984; Selby, 1985; IPT, 2005; Riffel et al., 2016). De acordo com Znamensky (2005) e Kanji et al. (2008), os movimentos definidos como fluxos ou corridas diferenciam-se dos demais movimentos de massa devido a características peculiares tais como: velocidade elevada, alta capacidade de erosão e destruição, e transporte de detritos a grandes distâncias em períodos de tempo muito curtos.

De acordo com Abe \& Konagai (2016) e Riffel et al. (2016), os fluxos de detritos são movimentos rápidos, que concentram muita energia, nos quais detritos, blocos de rochas e restos vegetais se deslocam encosta abaixo e ao longo das linhas de drenagem em vales declivosos. Este tipo de movimento de massa geralmente está associado a uma sequência de escorregamentos quase simultâneos e consecutivos, que se juntam nas linhas de drenagem e provocam a erosão e o transporte de blocos de rochas ao longo dos leitos dos rios, mobilizando uma grande quantidade de material, com energia e poder destrutivo muito elevado. Os fluxos estão geralmente associados à excessiva concentração dos fluxos de água superficiais, provenientes de precipitações anômalas, que deflagram em algum ponto da encosta um processo de fluxo de material terroso (Fernandes \& Amaral, 1996).

O IPT (2005) destaca ainda que os fluxos de detritos estão associados a intensas e volumosas precipitações, tendo um comportamento líquido viscoso e um alto poder de transporte. Estes fenômenos são menos frequentes que os deslizamentos e podem provocar consequências de magnitudes superiores, em função do seu alto poder destrutivo, sua velocidade (que dificulta as ações de remoção de bens e pessoas) e sua extensa área de alcance, mesmo em áreas mais planas e distantes (Highland \& Bobrowsky, 2008; Riffel et al., 2016).

A ocorrência e abrangência de eventos de movimentos de massa, muitas vezes, só é totalmente conhecida após o mapeamento das marcas deixadas no terreno, conhecidas na literatura científica como cicatrizes. Muitos trabalhos têm identificado essas cicatrizes com uso de fotografias aéreas e imagens obtidas por sensoriamento remoto, principalmente quando esses fenômenos ocorrem em áreas com difícil acesso (Okida, 1996; Sestini, 1999; Marcelino, 2003; Lopes, 2006; Riffel et al., 2016).

Diversas técnicas e métodos já foram utilizados para a identificação de áreas suscetíveis ou de risco a movimentos de massa, variando de acordo com a escala e o conjunto de dados disponível (Riffel et al., 2016; Melo \& Zêzere, 2017). De acordo com Fernandes et al. (2001), a modelagem e a previsão de áreas instáveis para a ocorrência de movimentos de massa podem ser desenvolvidas considerando: (i) análises a partir da distribuição dos movimentos de massa em inventário de cicatrizes obtidos em campo ou com uso de sensores remotos (Cheng et al., 2013; Scaioni et al., 2014); 
(ii) análises a partir de mapeamentos geomorfológicos e/ou geotécnicos, ou por álgebra de mapas digitais em Sistemas de Informações Geográficas - SIGs (Hearn, 1992; Lara et al., 1997); (iii) modelos determinísticos empíricos, com bases matemáticas e/ou estatísticas que consideram a relação entre as condicionantes explicativas e a ocorrência dos movimentos de massa (Zare et al., 2013; Conforti et al., 2014; Bui et al., 2016); (iv) modelos determinísticos conceituais, que consideram uma base física dos processos (He et al., 2014; Michel et al., 2014).

A modelagem e o mapeamento das áreas suscetíveis a deslizamentos e a fluxos de detritos são medidas essenciais para o planejamento de municípios que se desenvolvem em fundos de vales ou em vertentes íngremes. Essas medidas podem amenizar os danos decorrentes desses fenômenos em função de um novo reordenamento da expansão das cidades. Os mapas de suscetibilidade podem ser usados para subsidiar a reorganização do espaço urbano, sendo úteis para o estabelecimento de novas diretrizes de ocupação.

Considerando a importância do tema, o objetivo deste trabalho foi analisar e identificar as áreas suscetíveis a fluxos de detritos na bacia do Rio do Taquari-Antas, RS, a partir das semelhanças físicas e morfométricas com os pontos de ruptura (origem) dos movimentos de massa ocorridos em 2010.

\section{Materiais e métodos}

A metodologia para análise e mapeamento de áreas suscetíveis a fluxos de detritos na bacia hidrográfica do Rio Taquari-Antas compreendeu: (i) elaboração de inventário de cicatrizes relacionadas aos movimentos de massa; (ii) análise morfométrica das áreas de ocorrência de fluxos de detritos; (iii) modelagem das áreas suscetíveis por meio de uma abordagem probabilística; (iv) análise espacial, buscando identificar as sub-bacias e municípios mais suscetíveis. Uma expedição a campo foi realizada para a caracterização dos processos que ocorreram na bacia e para validação dos resultados.

\section{1 Área de estudo}

A área do presente estudo é a bacia hidrográfica do Rio Taquari-Antas (Fig. 1). Essa bacia encontra-se inserida entre as latitudes $28^{\circ} 10^{\prime} \mathrm{e}$ $29^{\circ} 57^{\prime} \mathrm{S}$ e as longitudes $49^{\circ} 55^{\prime}$ e $52^{\circ} 38^{\prime} \mathrm{O}$, em uma área de drenagem de $26.428 \mathrm{~km}^{2}$. 0 Rio Taquari -Antas pode ser subdividido em dois grandes trechos: (i) a porção a montante, sob a denominação de Rio das Antas, está predominantemente encaixado em um vale de relevo acidentado, alternando poços e corredeiras, eventualmente intercalados por saltos de pequeno porte, com seu percurso marcado por um forte controle estrutural; (ii) a porção a jusante, sob a denominação de Rio Taquari, onde o vale é formado predominantemente por depósitos colúvio-aluvionares, possuindo, em alguns trechos, extensas planícies e terraços fluviais.

$\mathrm{Na}$ bacia ocorrem processos hidrológicos extremos e distintos: no vale do Rio Taquari predominam as inundações, em virtude da grande dimensão da bacia e do elevado tempo de concentração das águas (superior a 48 h); nas bacias menores, referentes aos afluentes do Rio Taquari, como o Forqueta, o Guaporé e o Carreiro, por outro lado, predominam os movimentos de massa e as enxurradas, com tempo de concentração inferior a $24 \mathrm{~h}$, tendo-se em vista a presença de linhas de escarpa erosiva com declividades acentuadas e vales com rios bem encaixados (Ferri \& Togni, 2012).

No caso dos movimentos de massa e das enxurradas, os alertas dificilmente podem ser realizados com antecedência, o que dificulta a ação da Defesa Civil. Os prejuízos e as perdas materiais são mais concentrados no espaço (os eventos atingem áreas menores), porém são mais intensos devido à velocidade do processo, podendo ocasionar perdas humanas. A partir de imagens do programa Google Earth (Fig. 2) é possível observar dezenas de cicatrizes relacionadas a deslizamentos e fluxos de detritos ocorridos em janeiro de 2010, nos municípios de Barros Cassal, Fontoura Xavier e Soledade. Essas cicatrizes ainda não foram devidamente documentadas, nem estudadas. Relatos dos moradores de áreas rurais indicam que o evento no fundo do vale não se refere apenas a uma enxurrada, mas sim a uma sequência de fluxos de detritos que resultaram na maior enxurrada registrada no vale do rio Forqueta. 


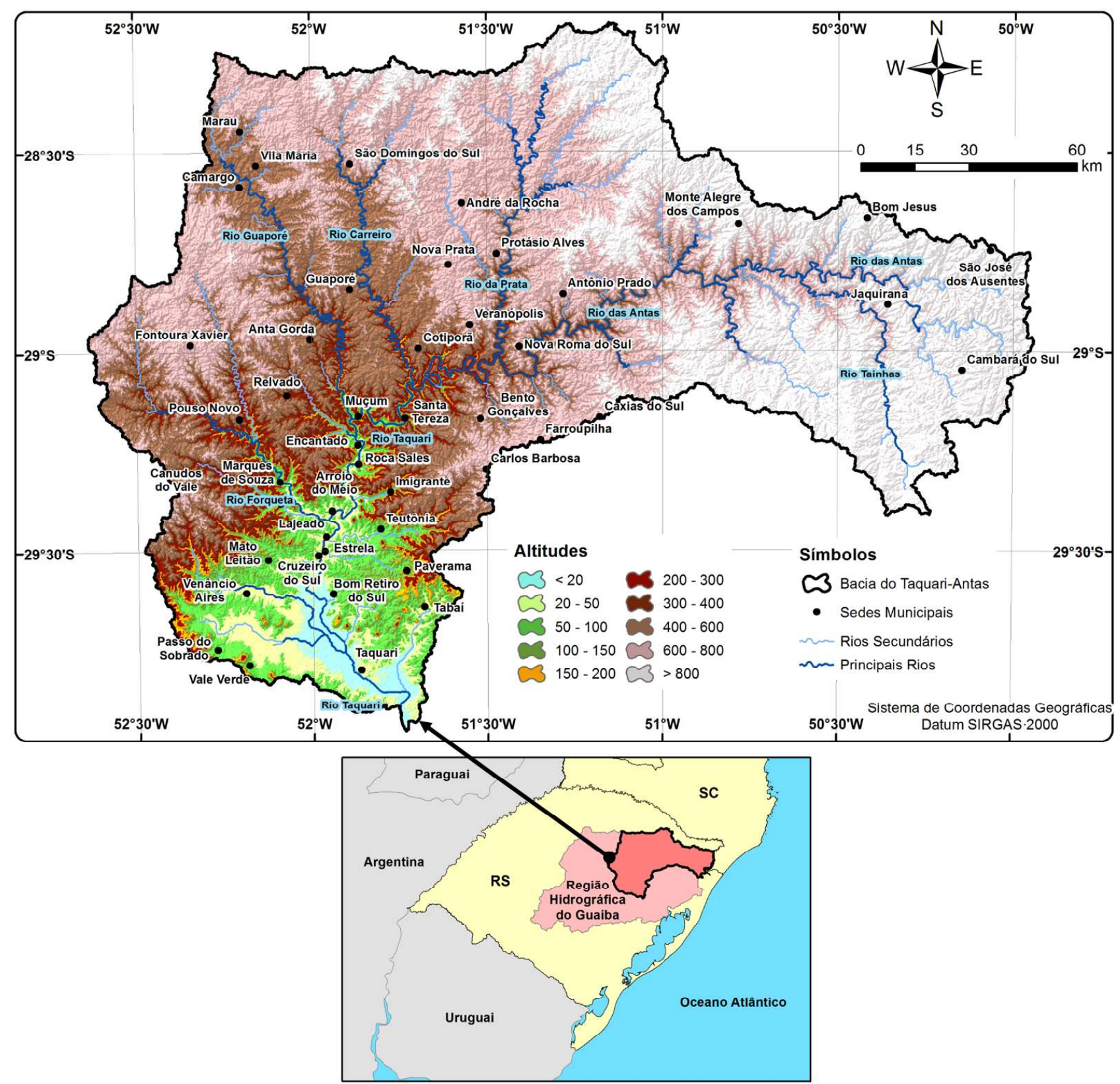

Figura 1. Localização da Bacia Hidrográfica do Rio Taquari-Antas, RS, Brasil.

Figure 1. Location of Taquari-Antas River Basin, RS, Brazil.

\subsection{Inventário de cicatrizes de fluxos de detritos}

A primeira etapa consistiu na construção de um inventário de cicatrizes, a partir de pesquisa bibliográfica, imagens orbitais, consulta a autoridades locais e atividades a campo. Por meio da consulta às autoridades locais, inicialmente foram identificadas apenas duas cicatrizes na bacia do Rio Taquari-Antas, localizadas nos municípios de Venâncio Aires e Jaquirana. Devido à inicial falta de dados, optou-se por utilizar como amostras outras áreas com ocorrências de fluxos de detritos localizadas na sub-bacia do Arroio Forromeco, na bacia do Rio Caí, resultantes de um evento de dezem- bro de 2000. Ressalta-se, como justificativas para a escolha desta área amostral, a presença de um número significativo de rupturas de grande porte, com possibilidade de identificação por imagens orbitais, além da relativa semelhança climática, geológica, pedológica e geomorfológica com a bacia de estudo. A bacia do Rio Caí é adjacente à bacia do Rio Taquari-Antas. Ambas estão localizadas entre o Planalto Meridional e as planícies do Rio Jacuí. Essas cicatrizes foram identificadas a partir das imagens disponíveis no programa Google Earth, do dia 06/04/2004. Por meio de interpretação visual, obteve-se, com relativa precisão, a localização do ponto de ruptura. Em relação a esse evento extremo hidrometeorológico, ocorrido no ano de 2000, 
foram identificadas 54 rupturas, 31 localizadas no município de Alto Feliz, 22 em Carlos Barbosa e 1 em São Vendelino.

Tendo a experiência anterior como base, e sabendo da ocorrência de uma enxurrada de grande magnitude em janeiro de 2010, foi realizada uma busca sistemática da origem dos detritos associados à maior enxurrada registrada na bacia dos rios Fão e Forqueta, a partir de pesquisa no Google Earth. Na inspeção visual das imagens, seguindo as linhas de drenagem em direção a montante, foram localizadas 137 cicatrizes entre os municípios de Fontoura Xavier, Barros Cassal, Soledade e Progresso, por meio de imagens datadas de 17/01/2012 e 11/05/2012. No total, foram identificadas e mapeadas 193 cicatrizes de movimentos de massa que desencadearam fluxos de detritos relacionadas a estes dois eventos e, em cada uma delas, foi identificado um ponto para representar a ruptura.

2.3 Análise morfométrica das áreas de ocorrências de fluxos de detritos

Os dados de sensoriamento remoto da Shuttle Radar Topography Mission (SRTM), uti- lizados para a geração de modelos digitais de superfície, são vastamente difundidos e possuem aplicações no âmbito de diagnósticos ambientais e de estudos relacionados às dinâmicas geomorfológicas e hidrológicas (Paz \& Collischonn, 2008; Valeriano, 2008; Brubacher et al., 2011). Tais dados configuram-se como uma alternativa na minimização de custos e de tempo em estudos de análise ambiental, uma vez que possibilitam, de forma rápida e eficiente, a extração de redes de drenagem e a análise morfométrica do terreno a partir de geoprocessamento.

Foi utilizada a base de dados SRTM, em versão refinada para o território brasileiro através do TOPODATA - Banco de Dados Geomorfométricos do Brasil (Valeriano, 2005, 2008), com resolução espacial de $30 \mathrm{~m}$. Foram obtidas, com base em Valeriano (2008), as seguintes camadas de informações espaciais: altimetria (m); declividades (\%); orientação do relevo e; formas do terreno.

A utilização dessa base se deve: à qualidade dos dados para representar o terreno em escalas de 1:100.000 a 1:250.000; à acessibilidade e à gratuidade, que garantem que a mesma metodologia possa ser reproduzida em outras bacias ou regiões. Uma vantagem da utilização do banco de

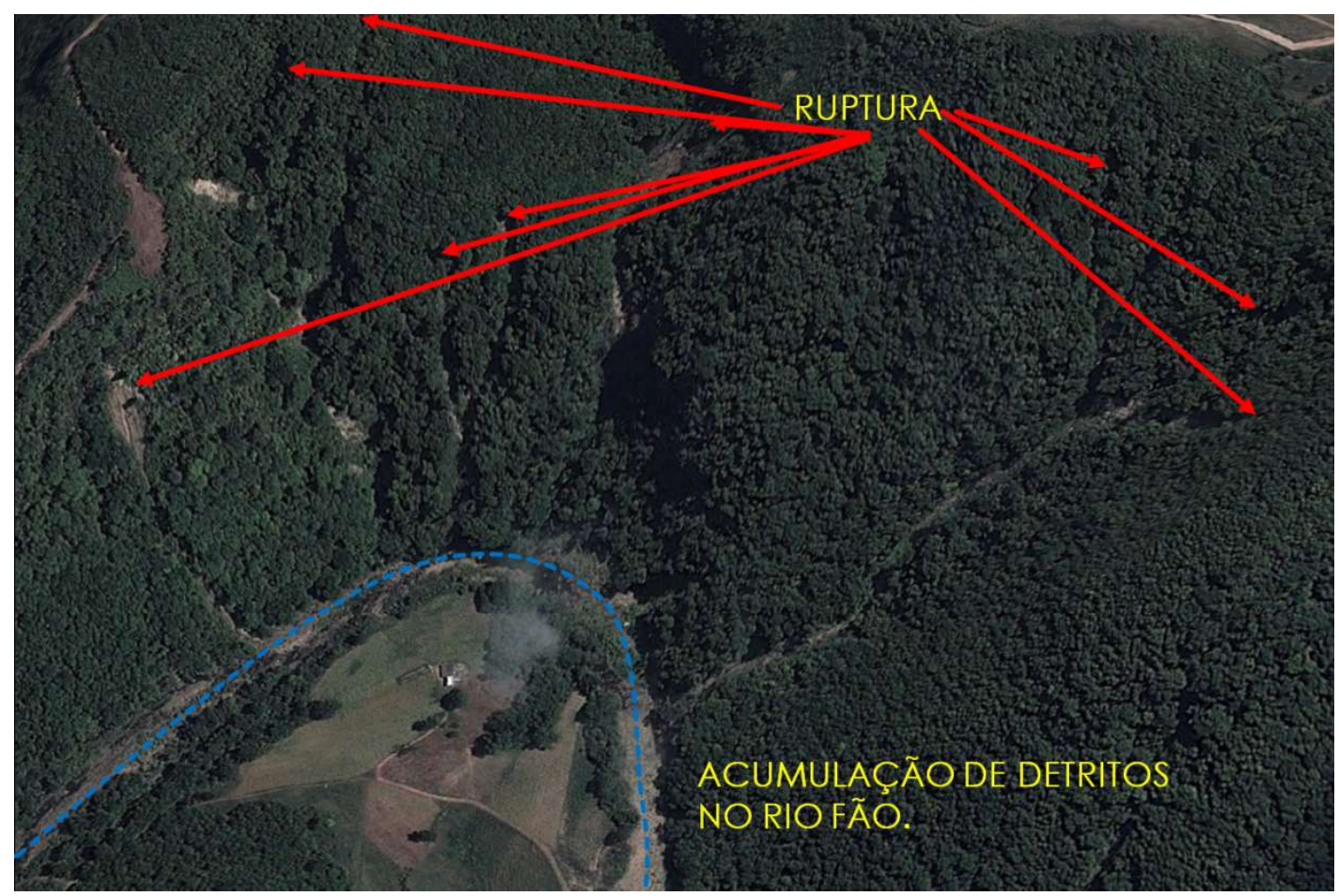

Figura 2. Exemplos de cicatrizes de movimentos de massa e de zonas de acúmulo de detritos, na bacia hidrográfica do Rio Forqueta, após janeiro de 2010 (Fonte: Google Earth).

Figure 2. Examples of mass movement scars and debris accumulation zones in the Forqueta River basin after January 2010. (Source: Google Earth). 
dados TOPODATA, em detrimento da base SRTM disponibilizada pela United States Geological Survey (USGS), portal EarthExplorer (https://earthexplorer.usgs.gov/), se refere ao fato do banco de dados TOPODATA não apresentar problemas de preenchimento de dados, uma vez que foram identificadas algumas lacunas nos dados originais SRTM na área de estudo, que só foram corrigidas na versão com resolução espacial de $90 \mathrm{~m}$.

Para a delimitação da bacia do Rio Taquari-Antas foi adotado o procedimento automatizado disponível no programa ArcGIS 10.2. 0 processo de extração de drenagem utiliza como base a direção de fluxo (Flow Direction), derivada da altimetria. A partir da direção de fluxo é gerada a área de drenagem acumulada (Flow Accumulation), em que cada píxel corresponde ao somatório das áreas superficiais de todos os píxeis que deságuam nele (Jenson \& Domingue, 1988; Paz \& Collischonn, 2008). A drenagem acumulada e a direção de fluxo são utilizadas na delimitação da bacia a partir de um ponto que representa a sua foz.

A altimetria foi utilizada também para obtenção das informações de desnível de morro, comprimento de rampa e desnível de rampa. 0 desnível de cada morro foi obtido através de um método automatizado, que consiste na inversão do MDE, a partir de uma operação de álgebra de mapas (Eq. 1). Com a inversão do MDE, os topos de morros e linhas de cumeada apresentam os menores valores, enquanto que os fundos de vale e as linhas de drenagem apresentam os maiores valores.

O segundo procedimento foi a obtenção das direções de fluxo (Flow Direction), considerando o MDE invertido, para identificar quais os píxeis associados a cada topo de morro ou linha de cumeada, do ponto de vista hidrológico. A partir das direções invertidas de fluxo é possível delimitar cada morro e suas respectivas linhas de cumeada por meio da extração de bacias hidrográficas. No ArcGIS, este procedimento é conhecido como Basin Flow. Uma vez que na base invertida as linhas de drenagem se comportam como divisores de água, a extração de bacias cria unidades relacionadas com topos de morros e linhas de cumeada.

$M D E_{i}=M a ́ x-M D E$

Em que: $\mathrm{MDE}_{\mathrm{i}}$ é o modelo digital de elevação in- vertido;

Máx é o valor máximo de elevação na base altimétrica original;

MDE é o modelo digital de elevação original.

Por fim, para a obtenção do desnível altimétrico em cada morro, é necessário extrair estatísticas para cada polígono de morro. No ArcGIS, este procedimento é conhecido como Zonal Statistics. Por meio desta ferramenta é possível obter valores mínimos, máximos, a amplitude, a moda, a média, a mediana e o desvio padrão dos valores altimétricos em cada unidade.

A segunda variável morfométrica obtida a partir da base altimétrica e da inversão do MDE foi o desnível altimétrico das rampas. Para tanto, foi extraído o menor valor altimétrico em cada polígono de morro. A partir disso, foi realizada uma operação de álgebra de mapas conforme a Equação 2:

\section{$D R=M D E-M i ́ n$}

Em que:

Mín é o menor valor altimétrico em cada morro; DR é o desnível altimétrico de rampa, de cada píxel do MDE em relação ao valor Mín.

A terceira variável morfométrica obtida a partir da base altimétrica e da inversão do MDE foi o comprimento de rampa. Para tanto, a partir das direções invertidas de fluxo, foi calculado o comprimento de drenagem (Flow Lenght) no ArcGIS. Este procedimento calcula a distância pela direção de fluxo entre cada píxel e a sua linha de drenagem respectiva.

As outras variáveis morfométricas consideradas neste estudo foram obtidas diretamente do banco de dados TOPODATA: (i) orientação das vertentes; (ii) formas do terreno; (iii) declividades. De acordo com a metodologia de Valeriano (2008), a combinação da curvatura horizontal (convergente, planar ou divergente) com a curvatura vertical (côncava, retilínea ou convexa) da superfície resultam nas formas do terreno. Essas formas do terreno foram combinadas, pixel a pixel, aos pontos de ruptura relacionados aos fluxos de detritos observadas nas áreas amostrais.

Nos dados de declividades foi testada a aplicação de um filtro de média, utilizando uma ja- 
nela móvel em cada pixel da imagem de declividades, para suavizar os contornos da base, buscando um padrão espacial melhor relacionado aos fluxos de detritos, uma vez que a ruptura foi representada em formato de ponto.

2.4 Modelagem e análise espacial das áreas suscetíveis

Nos últimos anos, diversos estudos tem sido realizados utilizando uma das abordagens acima mencionadas, tais como: Kanji et al. (2008), que analisaram as corridas de detritos em Cubatão; Monguilhott (2008), que estudou áreas suscetíveis a movimentos de massa na Rota do Sol (RS/486), na escarpa da Serra Geral do RS; Rocha (2011), que aplicou o modelo FLO-2D para simulação de corridas de detritos na região do Rio dos Cedros, SC; Pinheiro et al. (2012), que fizeram uma análise de instabilidade em uma encosta de Santa Cruz do Sul, RS; Riffel (2012), que mapeou as ocorrências de movimentos de massa na bacia do Rio Paranhana, RS; Vanacôr \& Rolim (2012), que mapearam a suscetibilidade a deslizamentos usando técnicas estatísticas na Serra Geral do RS, e; Pelizoni (2014), que analisou os fluxos de detritos na região serrana fluminense.

De modo geral, a modelagem, o mapeamento e a predição de áreas suscetíveis para a ocorrência de movimentos de massa podem ser desenvolvidos, considerando: (i) análises a partir da distribuição dos movimentos de massa em inventário de cicatrizes obtidos em campo ou com uso de sensores remotos (Cheng et al., 2013; Scaioni et al., 2014); (ii) análises a partir de mapeamentos geomorfológicos e/ou geotécnicos, ou por álgebra de mapas digitais em SIGs (Hearn, 1992; Lara et al., 1997); (iii) modelos determinísticos empíricos, com bases matemáticas e/ou probabilísticas, que consideram a relação entre as condicionantes explicativas e a ocorrência dos movimentos de massa (Zare et al., 2013; Conforti et al., 2014; Bui et al., 2016); (iv) modelos determinísticos conceituais, que consideram parcialmente ou totalmente uma base física dos processos (He et al., 2014; Michel et al., 2014).

A abordagem metodológica escolhida neste estudo foi a probabilística, tendo em vista a obtenção do inventário e dos atributos morfométricos. Todas as variáveis mencionadas foram combinadas aos pontos de ruptura, uma por cicatriz, para análise e modelagem estatística. Esses atributos foram quantificados em cada ponto de ruptura que originou fluxo de detritos, tanto na bacia do Rio Caí quanto na bacia do Taquari-Antas. A escolha desta abordagem se deve: à escala de análise (bacia de grandes dimensões, com mais de 26 mil $\mathrm{km}^{2}$ ); à ausência de dados de alta resolução espacial que cubram toda a área da bacia (inviabilizando o uso de modelos conceituais); e à ausência de estudos abrangentes na área de estudo, definindo limiares e critérios precisos para a ocorrência de fluxos de detritos.

Os limiares e critérios estabelecidos na literatura científica nacional e internacional para o mapeamento de áreas suscetíveis a este tipo de movimento de massa se referem, normalmente, a locais com características climáticas, geológicas, geomorfológicas e morfométricas muito diferentes das observadas na bacia do Taquari-Antas. Dessa forma, optou-se pela abordagem estatística, considerando somente o conjunto de amostras dos eventos observados na área de estudo e adjacências, e sua relação com os atributos do terreno extraídos do MDE. Embora isso implique em uma simplificação dos fenômenos físicos envolvidos, uma vez que desconsidera outras bases cartográficas de cunho físico (como solos, geologia, uso e cobertura da terra, entre outras), tal procedimento foi julgado como o mais adequado do que estabelecer critérios subjetivos baseados em áreas com aspectos morfométricos diferentes da área deste estudo.

Com base nos resultados da análise morfométrica realizada na etapa anterior, optou-se por utilizar os atributos morfométricos que apresentaram um comportamento de frequência e distribuição possível de ser modelado com o ajuste de distribuições probabilísticas conhecidas, tais como a distribuição Normal, Log-Normal, Weibull, Gumbel, Gamma, entre outras. A modelagem estatística consiste no ajuste de uma distribuição de probabilidades às amostras de rupturas obtidas no inventário, em relação a cada um dos três atributos. Essas distribuições de probabilidades foram testadas, ajustadas e validadas pelo teste de aderência não paramétrico de Kolmogorov-Smirnov 
(Hollander \& Wolfe, 1999), utilizando o programa MATLAB R2010a. A distribuição que apresentou a melhor aderência aos dados amostrais foi selecionada para a modelagem.

Os limiares de probabilidade dos atributos morfométricos para definir as áreas suscetíveis a fluxos de detritos e seus respectivos graus de suscetibilidade na bacia do Rio Taquari-Antas foram estabelecidos em função do erro de omissão obtido nas áreas amostrais, das bacias dos rios Caí e Taquari-Antas. Quanto menor o erro de omissão pretendido, maior deve ser o limiar de intervalo de confiança escolhido e mais abrangente se torna o intervalo de valores dos três atributos para espacializar as áreas suscetíveis. Optou-se por limiares mais estreitos e rigorosos na medida em que aumenta o grau de suscetibilidade, para que a delimitação de áreas de alta suscetibilidade não seja abrangente demais a ponto de generalizar o fenômeno.

Deste modo, após diversos testes, optou-se pelos seguintes limiares: (i) intervalo de confiança de $75 \%$ para as áreas de alta suscetibilidade, com erro de omissão de aproximadamente 50\%; (ii) intervalo de confiança de $95 \%$ para as áreas de média suscetibilidade, com erro de omissão de aproximadamente 10\%; (iii) intervalo de confiança de 99\% para as áreas de baixa suscetibilidade, com erro de omissão de aproximadamente $1 \%$. Ao adotar esses limiares, cerca de $50 \%$ das amostras são devidamente identificadas em áreas de alta suscetibilidade, cerca de $90 \%$ são identificadas em áreas de média ou alta suscetibilidade e 99\% das amostras ficam em áreas com algum grau de suscetibilidade (de baixa a alta).

A metodologia empregada no presente es-

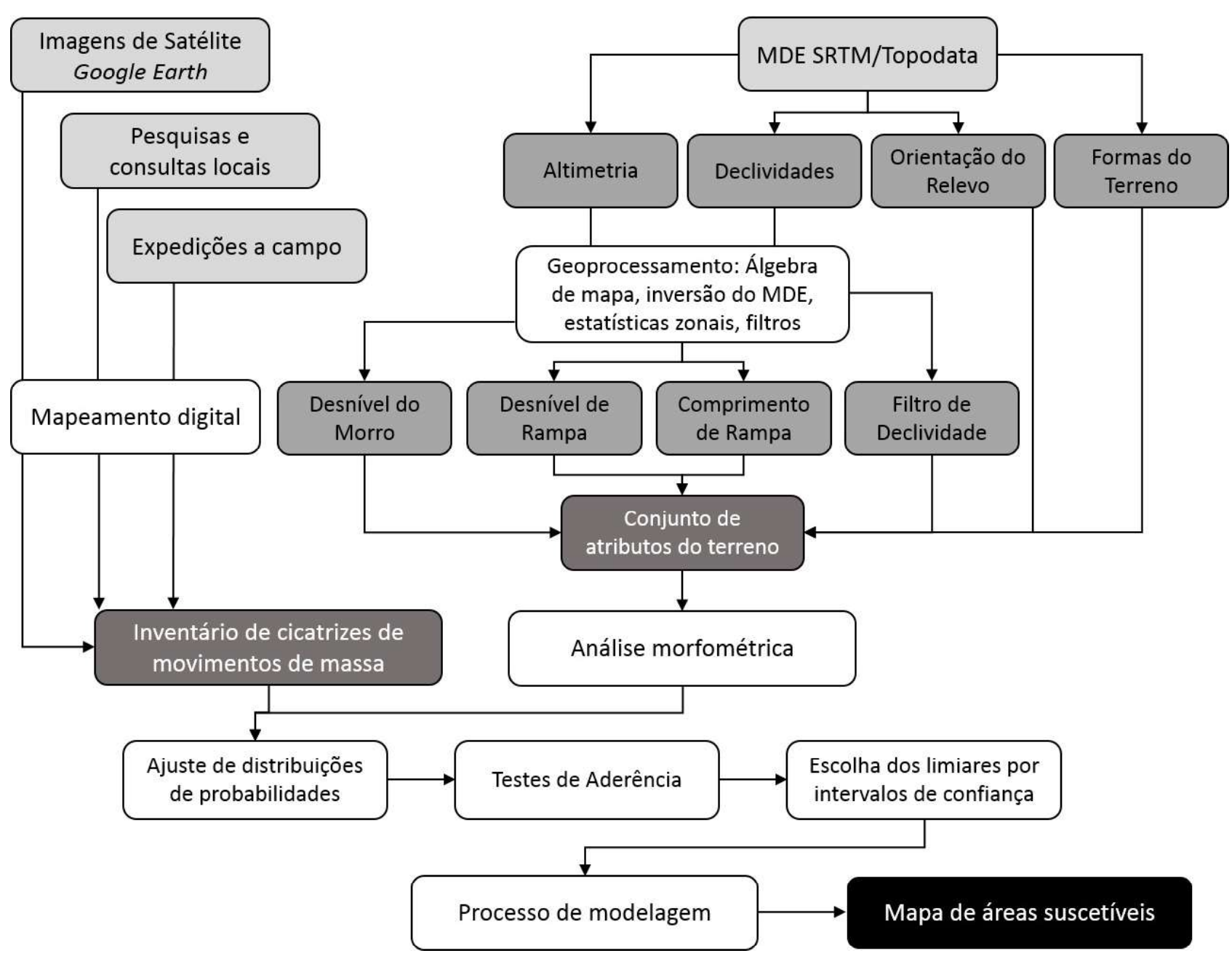

Figura 3. Fluxograma dos métodos adotados no estudo. Figure 3. Flowchart of the methods adopted in the study. 
tudo, com a sequência de procedimentos e etapas, é sintetizada no fluxograma apresentado na figura 3 .

\section{Resultados e discussões}

As cicatrizes mapeadas de deslizamentos apresentam uma área total de 27,3 hectares, a maioria delas com comprimento superior a $150 \mathrm{~m}$ e largura na ordem de $10 \mathrm{~m}$. Nas cicatrizes visitadas em atividades de campo, pode-se observar que se tratam de deslizamentos rasos, com profundidade normalmente inferior a $1 \mathrm{~m}$.

A tabela 1 apresenta a distribuição de frequência das rupturas inventariadas em função dos intervalos de desnível altimétrico dos morros. Destaca-se que a maior parte das rupturas $(71,5 \%)$ ocorreu em morros com desnível entre 200 e 400 m. 0 valor médio de desnível altimétrico foi de $316,5 \mathrm{~m}$, com desvio padrão de $104 \mathrm{~m}$, resultando em um coeficiente de variação (CV) de apenas 0,33. Isso indica que os valores de desnível altimétricos apresentam pouca dispersão em torno da média, o que facilita a adoção de uma abordagem probabilística para o tratamento destes dados a fim de obter limiares para o mapa de suscetibilidade na área de estudo.

A tabela 2 apresenta a frequência das rupturas em função dos intervalos de desnível altimétrico das rampas. Pode-se observar que o intervalo entre 100 e 200 m de desnível de rampa concentra grande parte das rupturas, totalizando 89 ocorrências, equivalente a $46 \%$. Ampliando o intervalo, constata-se que 165 rupturas $(85,5 \%)$ ocorreram em locais com desnível altimétrico de rampa inferior a $300 \mathrm{~m}$. 0 valor médio de desnível altimétrico das rampas nos locais com ruptura foi de $183 \mathrm{~m}$, com desvio padrão de $113 \mathrm{~m}$, resultando em um

Tabela 1. Frequência das rupturas relacionadas a fluxos de detritos em função dos intervalos de desnível altimétrico dos morros, nas bacias hidrográficas dos rios Taquari-Antas e Caí, RS.

Table 1. Frequency of the ruptures related to the debris flow due to the altimetric gap interval of hill, in the Taquari-Antas and Caí River basins, $R S$.

\begin{tabular}{ccc}
\hline Intervalos de Desnível do Morro $(\mathrm{m})$ & Número de Rupturas & Proporção (\%) \\
\hline$<100$ & 0 & 0 \\
$100-200$ & 23 & 12 \\
$200-300$ & 68 & 35 \\
$300-400$ & 70 & 36 \\
$400-500$ & 16 & 8 \\
$>500$ & 16 & 8 \\
\hline Total & 193 & 100 \\
\hline
\end{tabular}

Tabela 2. Frequência das rupturas relacionadas a fluxos de detritos em função dos intervalos de desnível altimétrico das rampas, nas bacias hidrográficas dos rios Taquari-Antas e Caí, RS.

Table 2. Frequency of the ruptures related to the debris flow as a function of the altimetric gap interval of the ramps, in the Taquari-Antas and Caí River Basins, RS.

\begin{tabular}{ccc}
\hline Intervalos de Desnível de Rampa (m) & Número de Rupturas & Proporção (\%) \\
\hline$<100$ & 45 & 23 \\
$100-200$ & 89 & 46 \\
$200-300$ & 31 & 16 \\
$300-400$ & 15 & 8 \\
$400-500$ & 10 & 5 \\
$>500$ & 3 & 2 \\
\hline Total & 193 & 100 \\
\hline
\end{tabular}


coeficiente de variação (CV) de 0,62.

A tabela 3 apresenta a frequência das rupturas em relação ao comprimento de rampa. Pode-se observar que o intervalo com comprimentos de rampa inferiores a $400 \mathrm{~m}$, concentra boa parte das rupturas, totalizando 161 ocorrências, equivalente a $83 \%$. 0 valor médio de comprimento de rampa nos locais com ruptura foi de $265,5 \mathrm{~m}$, com desvio padrão de $326,4 \mathrm{~m}$, resultando em um coeficiente de variação $(C V)$ de 1,23. Estes resultados indicam que a variável comprimento de rampa apresenta um comportamento que dificulta a adoção de uma abordagem probabilística a fim de obter limiares para o mapa de suscetibilidade na área de estudo.

A tabela 4 apresenta a frequência das rup- turas em função da orientação das vertentes. Ao analisar os dados da tabela fica evidente a ausência de uma relação clara entre os fluxos e a base de orientação das vertentes. As vertentes com orientação oeste, leste e sudeste concentraram a maior parte das rupturas, somando 107 ocorrências, equivalente a $55 \%$.

$\mathrm{Na}$ área de estudo, ficou claro que a orientação das vertentes não determina a ocorrência de fluxos de detritos, uma vez que existem rupturas em todas as direções. Esse comportamento já havia sido constatado no estudo de Paulino (2013) que aplicou um modelo para a ocorrência de deslizamentos em Santa Catarina, com base no inventário de cicatrizes do evento extremo ocorrido em 2008. 0 autor constatou que havia cicatrizes em

Tabela 3. Frequência das rupturas relacionadas a fluxos de detritos em função dos intervalos de comprimento de rampa, bacias hidrográficas dos rios Taquari-Antas e Caí, RS.

Table 3. Frequency of the ruptures related to the debris flow as a function of the ramp length intervals, the Taquari-Antas and Cai River Basins, $R S$.

\begin{tabular}{ccc}
\hline Intervalos de Comprimento de Rampa (m) & Número de Rupturas & $\begin{array}{c}\text { Proporção } \\
(\%)\end{array}$ \\
\hline$<100$ & 53 & 27 \\
$100-200$ & 49 & 25 \\
$200-300$ & 34 & 18 \\
$300-400$ & 25 & 13 \\
$400-500$ & 7 & 4 \\
$500-600$ & 5 & 3 \\
$600-700$ & 4 & 2 \\
$700-800$ & 6 & 3 \\
$>800$ & 10 & 5 \\
\hline Total & 193 & 100 \\
\hline
\end{tabular}

Tabela 4. Frequência das rupturas relacionadas a fluxos de detritos em função da orientação das vertentes, nas bacias hidrográficas dos rios Taquari-Antas e Caí, RS.

Table 4. Frequency of the ruptures related to the debris flow according to the orientation of the slopes, in the Taquari-Antas and Caí River Basins, RS.

\begin{tabular}{ccc}
\hline Orientação do Relevo & Número de Rupturas & Proporção (\%) \\
\hline Norte & 14 & 7 \\
Nordeste & 19 & 10 \\
Leste & 31 & 16 \\
Sudeste & 32 & 17 \\
Sul & 14 & 7 \\
Sudoeste & 23 & 12 \\
Oeste & 44 & 23 \\
Noroeste & 16 & 8 \\
\hline Total & 193 & 100 \\
\hline
\end{tabular}


todas as direções de orientação, com maior frequência nas vertentes da direção norte.

Paulino (2013) argumenta que as vertentes mais úmidas, com menor exposição à radiação solar, são mais suscetíveis aos movimentos de massa. Porém, tal comportamento não parece ser determinante para a ocorrência de fluxos de detritos, especificamente, nas bacias hidrográficas do rio Caí e do rio Taquari-Antas, uma vez que as vertentes do quadrante sul (menor exposição ao Sol) não apresentaram maior concentração de rupturas (Tab. 4).

$\mathrm{Na}$ literatura científica alguns autores (Troeh, 1965; Bloom, 1970; Christofoletti, 1980; Silveira, 2008) avaliaram as formas das vertentes. Normalmente, as vertentes com curvatura horizontal convergente são mais suscetíveis à ocorrência de movimentos de massa, por apresentarem a concentração do fluxo e solos relativamente mais espessos. Porém, tal fenômeno não foi observado nas áreas amostrais relacionadas aos pontos de ruptura localizados nas bacias dos rios Taquari -Antas e Caí, como pode ser observado na tabela 5. As vertentes divergentes apresentaram um grande número de rupturas (84), perfazendo $44 \%$ das ocorrências. Quanto à curvatura vertical, o predomínio de rupturas ocorreu em vertentes convexas, com 100 amostras (52\%). A forma do terreno mais destacada quanto às rupturas que desencadearam os fluxos de detritos nas áreas amostrais foi a divergente-convexa, totalizando 51 ocorrências, ou $26 \%$ dos fluxos.

É importante ressaltar que, embora a ruptura possa ocorrer em praticamente todas as formas do terreno, a massa de detritos apresenta um deslocamento fortemente associado às direções de fluxo, tendendo a concentrar os detritos em áreas de curvatura convergente. Porém, uma vez que o interesse é espacializar áreas suscetíveis à ocorrência de fluxos de detritos, relacionadas ao ponto de ruptura do ter-

Tabela 5. Frequência das rupturas relacionadas a fluxos de detritos em função das formas do terreno, nas bacias hidrográficas dos rios Taquari-Antas e Caí, RS.

Table 5. Frequency of the ruptures related to the debris flow due to the terrain forms, in the Taquari-Antas and Caí River Basins, RS.

\begin{tabular}{ccc}
\hline Formas do Terreno & Número de Rupturas & Proporção (\%) \\
\hline Convergente-Côncava & 35 & 18 \\
Convergente-Retilínea & 2 & 1 \\
Convergente-Convexa & 20 & 10 \\
Planar-Côncava & 22 & 11 \\
Planar-Retilínea & 1 & 1 \\
Planar-Convexa & 29 & 15 \\
Divergente-Côncava & 29 & 15 \\
Divergente-Retilínea & 4 & 2 \\
Divergente-Convexa & 51 & 26 \\
\hline Total & 193 & 100 \\
\hline
\end{tabular}

reno, não é possível descartar nenhum tipo de curvatura no processo de caracterização dos eventos.

A figura 4 apresenta a frequência das rupturas relacionadas a fluxos de detritos em função dos intervalos de declividades, após a aplicação de um filtro de média em uma janela móvel $5 \times 5$. 0 filtro foi aplicado uma vez observado um comportamento bimodal na distribuição de frequência das declividades brutas nos pontos amostrais. Visando suavizar esse comportamento, foi testada a aplicação de um filtro de média, utilizando duas janelas móveis ( $3 \times 3$ e $5 \times 5)$ em toda a imagem de declividades. Ao analisar os resultados, foi possível constatar que a aplicação de filtros reduz a dispersão dos valores obtidos de declividades para os pontos de ruptura. Com a aplicação de um filtro de média em uma janela $5 \times 5$ (Fig. 4), todas as rupturas ocorreram em declividades entre $10 \%$ e $55 \%$, com predominância de fluxos de detritos com declives entre $25 \%$ e $55 \%$, com 183 casos (95\%).

Utilizando a janela $5 \times 5$ para a aplicação do filtro, a distribuição de frequência perde o com- 
portamento bimodal, o que facilita a aplicação de distribuições estatísticas para a modelagem de áreas suscetíveis. Além disso, em uma análise estatística exploratória, pode-se observar que o coeficiente de variação dos dados de declividades reduz na medida em que aumenta a janela do filtro aplicado. Esses resultados evidenciam que a aplicação de filtros na base de declividades para extrair um comportamento geral das rupturas em função desta variável morfométrica pode ser benéfica, pois permite reduzir a variabilidade dos valores críticos para a ocorrência de fluxos de detritos.

Com base nos resultados obtidos na etapa de análise dos atributos do terreno, foram selecionados três atributos morfométricos para a modelagem espacial: (i) declividades filtradas pela média em janela $5 \times 5$; (ii) desnível altimétrico da rampa; (iii) desnível altimétrico do morro. Estes atributos apresentaram uma tendência central bem definida, baixa dispersão dos dados, e baixa correlação entre si (inferior a 0,55), garantindo a independência entre os três atributos, o que é de- sejável para a modelagem estatística do fenômeno na área de interesse.

Quanto à modelagem estatística, para o atributo de declividades, a distribuição que apresentou o melhor ajuste às amostras foi a distribuição de probabilidades generalizada para valores extremos (GEV). A figura 5 ilustra a aderência dos dados amostrais à distribuição.

Considerando o ajuste estatístico em relação às declividades, pode-se estimar que apenas $5 \%$ das ocorrências de fluxos de detritos foram deflagradas em declividades iguais ou inferiores a $25 \%$. Do mesmo modo, estimou-se que 95\% das ocorrências são deflagradas em declividades iguais ou inferiores a 49,8\%. Com base nisso, pode-se afirmar, com $90 \%$ de confiança, que as rupturas para fluxos de detritos acontecem no intervalo entre $25 \%$ e $50 \%$ de declividades.

Para o atributo de desnível altimétrico da rampa, a distribuição que apresentou o melhor ajuste às amostras também foi a distribuição de probabilidades generalizada para valores extre-

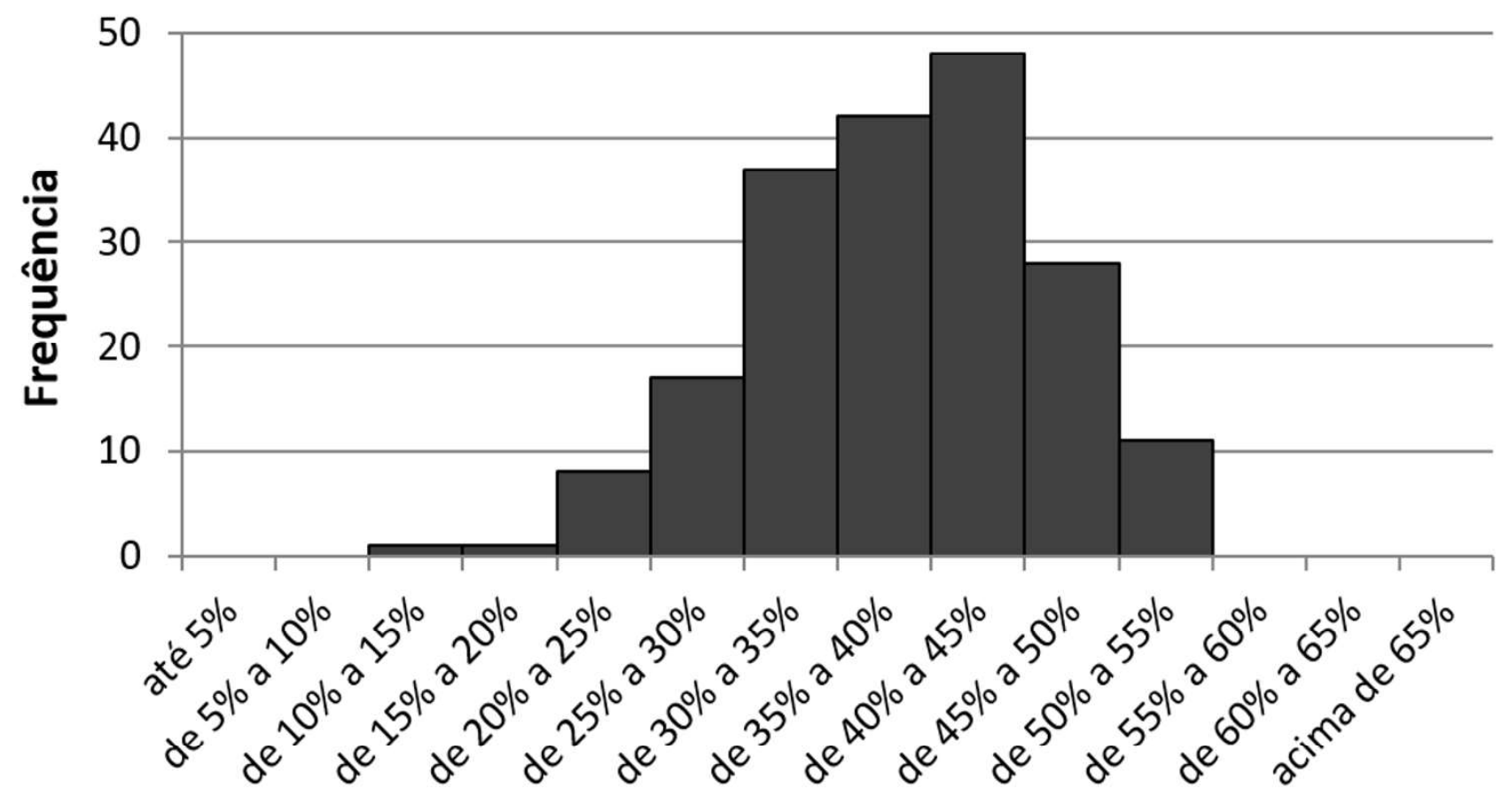

\section{Classes de Declividade (filtro de média 5x5)}

Figura 4. Frequência das rupturas relacionadas a fluxos de detritos em função dos intervalos de declividades filtradas pela média (janela 5x5), nas bacias dos rios Taquari-Antas e Caí, RS.

Figure 4. Frequency of the ruptures related to the debris flow as a function of the intervals of gradients filtered by the mean (window 5x5), in the Taquari-Antas and Caí River Basins, RS. 


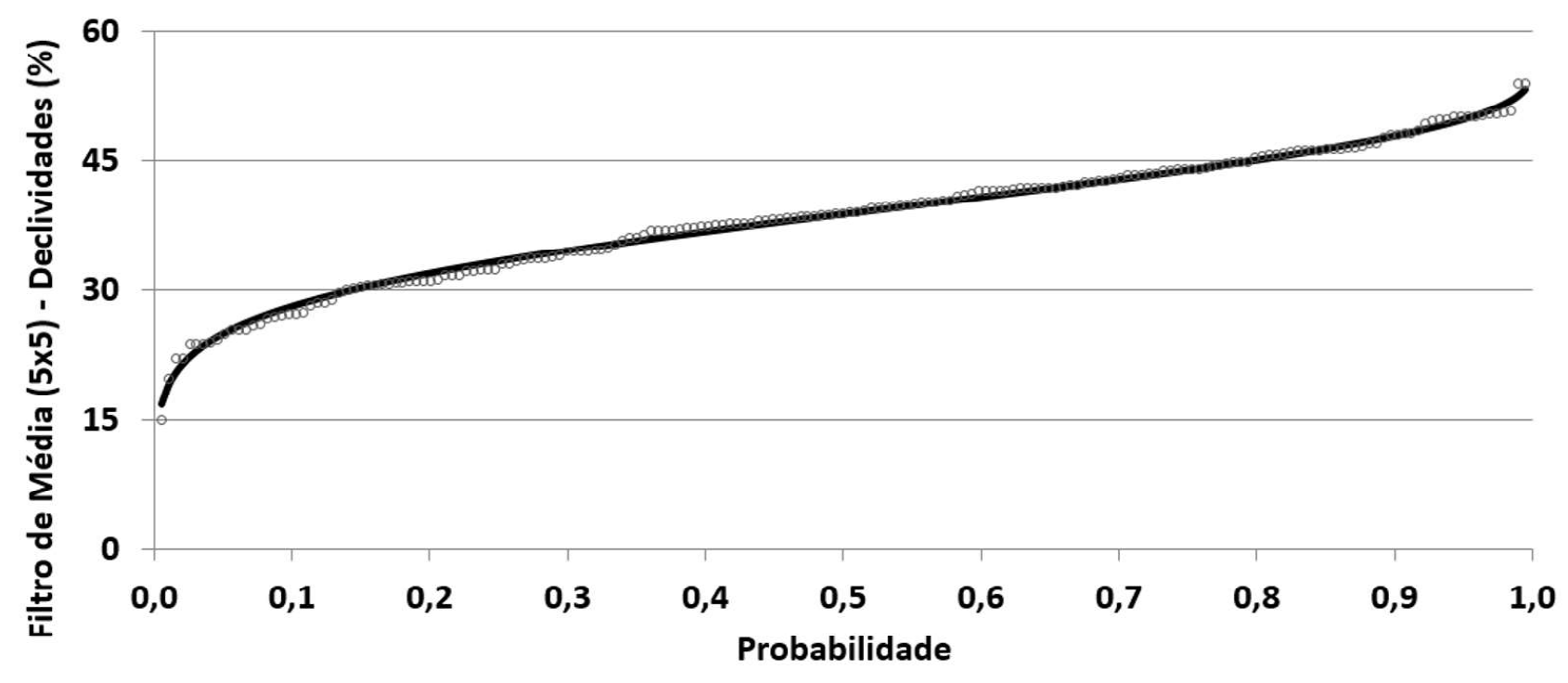

—Ajuste: Distribuição GEV

Amostras: valores observados

Figura 5. Ajuste da distribuição generalizada para valores extremos (GEV) às rupturas que desencadearam fluxos de detritos nas bacias dos rios Caí e Taquari-Antas, em função da declividade filtrada pela média (janela 5x5).

Figure 5. Adjustment of the generalized distribution to extreme values (GEV) to the rupture data that triggered debris flow in the Caí and the Taquari-Antas Rivers basins, as a function of the slope filtered by the mean (window 5x5).

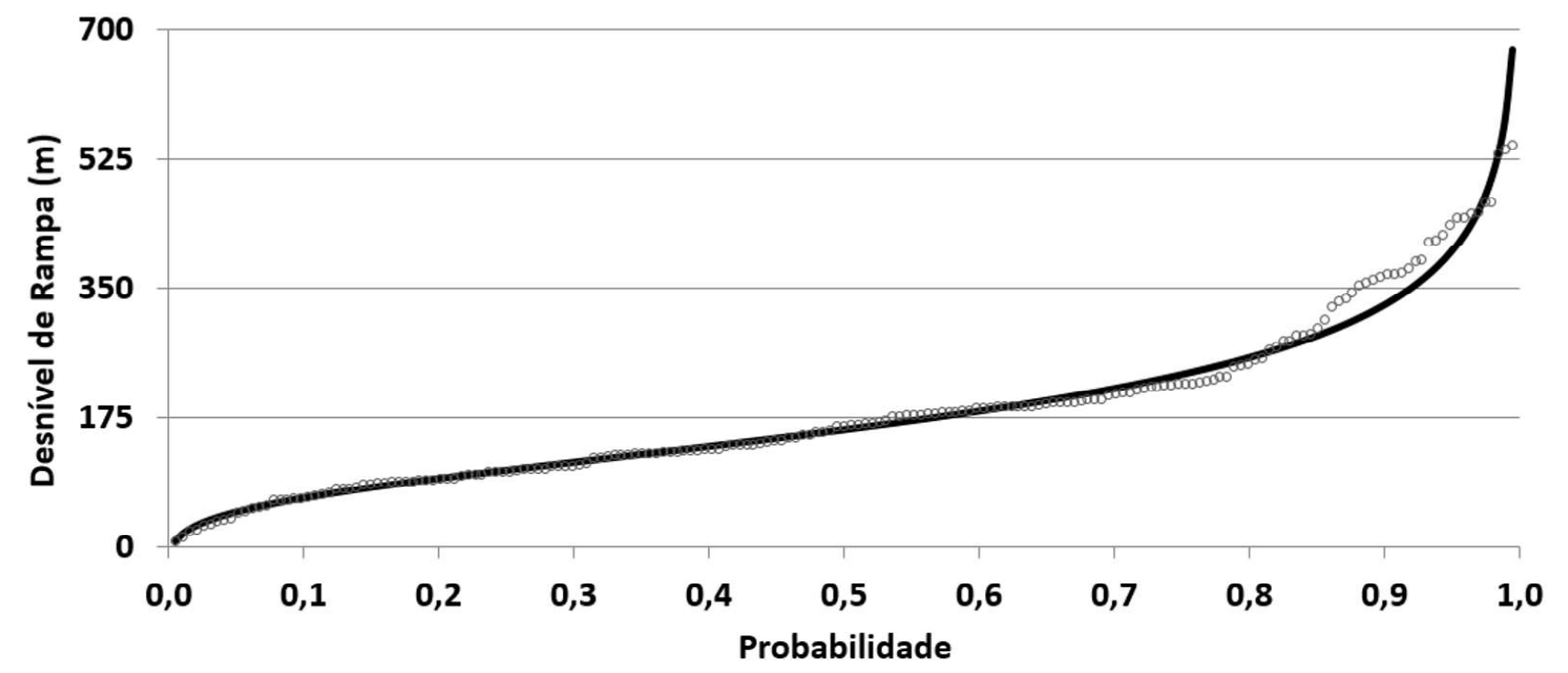

Figura 6. Ajuste da distribuição generalizada para valores extremos (GEV) às rupturas que desencadearam fluxos de detritos nas bacias dos rios Caí e Taquari-Antas, em função do desnível altimétrico da rampa.

Figure 6. Adjustment of the generalized distribution to extreme values (GEV) to rupture data that triggered debris flow in the Cai and the Taquari-Antas rivers basins, due to the altimetric slope of the ramp.

mos (GEV). A figura 6 demonstra a aderência dos dados amostrais à distribuição.

Considerando o ajuste estatístico em relação ao desnível altimétrico da rampa, pode-se estimar que apenas 5\% das ocorrências são deflagradas em rampas com desnível altimétrico em relação à linha de drenagem igual ou inferior a 47 m. Do mesmo modo, estima-se que $95 \%$ das ocorrências são deflagradas em rampas com desnível altimétrico em relação à linha de drenagem igual ou inferior a $400 \mathrm{~m}$. Ou seja, com base nesse modelo, pode-se afirmar, com $90 \%$ de confiança, que as rupturas para fluxos de detritos provavelmente acontecem em rampas com desnível altimétrico entre 50 e $400 \mathrm{~m}$, aproximadamente.

Por fim, para o atributo de desnível altimétrico dos morros, a distribuição que apresentou o melhor ajuste às amostras também foi a distribuição de 
probabilidades Gaussiana Inversa. A figura 7 ilustra a aderência dos dados amostrais à distribuição.

Levando-se em consideração o ajuste estatístico realizado em relação ao desnível altimétrico dos morros pode-se estimar que apenas $5 \%$ das ocorrências são deflagradas em morros com desnível altimétrico igual ou inferior a $175 \mathrm{~m}$. Do mesmo modo, estima-se que $95 \%$ das ocorrências são deflagradas em morros com desnível altimétrico igual ou inferior a $516 \mathrm{~m}$. Isto é, considerando o modelo, pode-se afirmar, com $90 \%$ de confiança, que as rupturas para flu- xos de detritos acontecem em morros com desnível altimétrico entre 175 e 515 m, aproximadamente.

A tabela 6 apresenta os graus de suscetibilidade a fluxos de detritos em função do erro de omissão aceitável em cada categoria e do limiar de intervalo de confiança adotado. A adoção desses limiares resulta em um modelo capaz de generalizar melhor as áreas suscetíveis para toda a bacia, uma vez que apenas os pixels com características que tendem ao comportamento mais próximo da média das amostras serão caracterizados como de alta suscetibili-

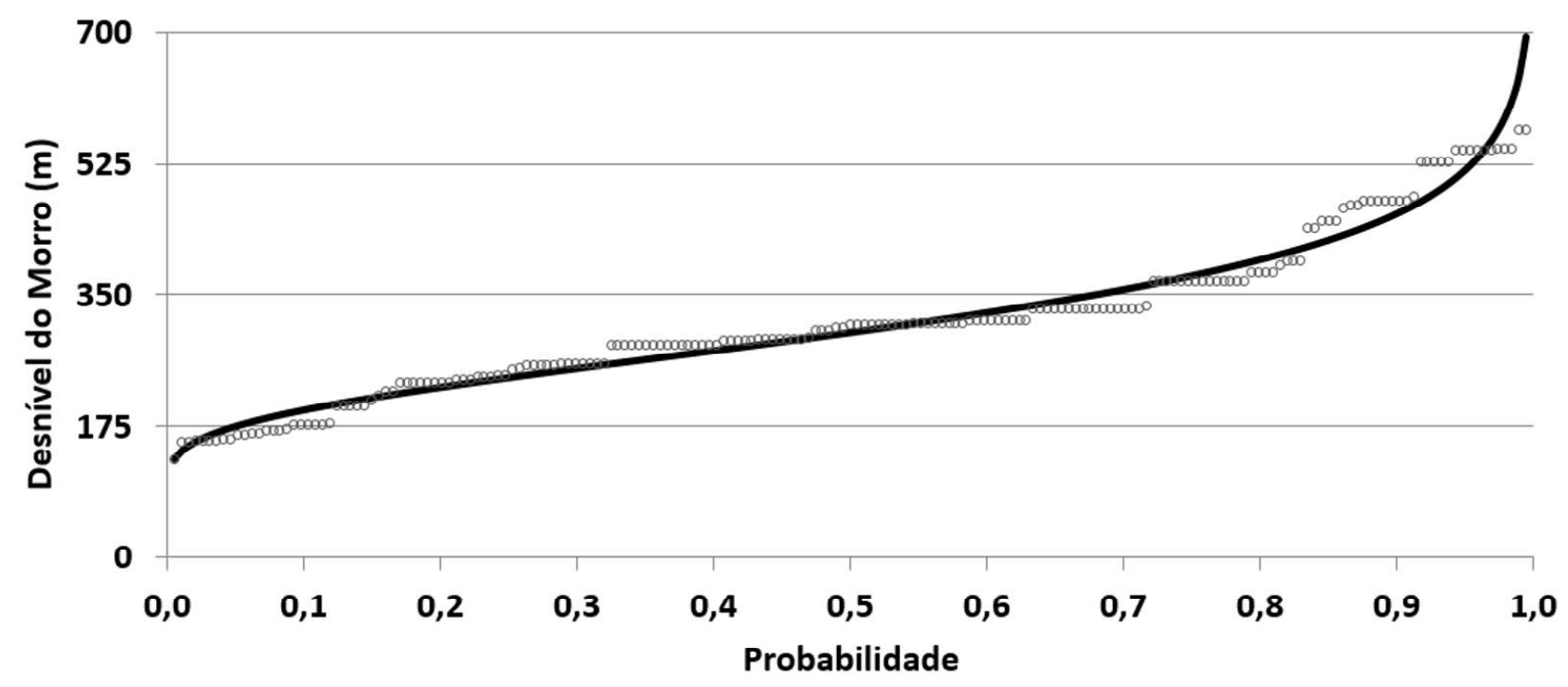

-Ajuste: distribuição Gaussiana Inversa

- Amostras: valores observados

Figura 7. Ajuste da distribuição Gaussiana Inversa às rupturas que desencadearam fluxos de detritos nas bacias dos rios Caí e Taquari-Antas, em função do desnível altimétrico dos morros.

Figure 7. Adjustment of the Inverse Gaussian distribution to rupture data that triggered debris flow in the Caí and Taquari-Antas rivers basins, due to the altimetric slope of the hills.

dade, sendo os valores mais extremos classificados na categoria de baixa suscetibilidade.

Para as áreas de alta suscetibilidade foi adotado o limiar de $75 \%$ para o tamanho do intervalo de confiança para os três atributos morfométricos, o que resultou em um erro de omissão de 47\%. Ao adotar esse limiar, 103 das 193 amostras de rupturas foram devidamente identificadas em áreas de alta suscetibilidade.

Para as áreas de média suscetibilidade foi adotado o limiar de 95\% para o intervalo de confiança para os três atributos morfométricos, o que resultou em um erro de omissão de $11 \%$, somando-se à área de alta suscetibilidade já identificada. Ao adotar esse limiar, 172 de 193 amostras foram devidamente identificadas em áreas de média ou alta suscetibilidade.
Por fim, para as áreas de baixa suscetibilidade foi adotado o limiar de 99\% para o tamanho do intervalo de confiança para os três atributos morfométricos, o que resultou em um erro de omissão de apenas $2 \%$, somando-se às áreas de alta e média suscetibilidade já reconhecidas. Ao adotar esse limiar, apenas quatro amostras de rupturas não foram identificadas em áreas de baixa, média ou alta suscetibilidade (acurácia global de $98 \%)$.

Considerando os intervalos de confiança estabelecidos, na tabela 7 são apresentados os intervalos de valores de declividades, desnível de rampa e desnível de morros para obtenção das áreas suscetíveis na bacia hidrográfica do Rio Taquari-Antas, RS. Para obtenção do mapa final, uma vez que as áreas são acumuladas entre os diferen- 
Tabela 6. Graus de suscetibilidade a fluxos de detritos na bacia hidrográfica do Rio Taquari-Antas, em função do erro de omissão e do limiar de intervalo de confiança.

Table 6. Susceptibility degrees to the debris flow in the Taquari-Antas River basin, due to the omission error and the confidence interval threshold.

\begin{tabular}{ccc} 
Suscetibilidade & $\begin{array}{c}\text { Erro de Omissão } \\
\text { (acumulado) }\end{array}$ & $\begin{array}{c}\text { Intervalo de } \\
\text { Confiança (limiar) }\end{array}$ \\
\hline Baixa & $2 \%$ & $99 \%$ \\
Média & $11 \%$ & $95 \%$ \\
Alta & $47 \%$ & $75 \%$ \\
\hline
\end{tabular}

Tabela 7. Intervalos de declividades, desnível de rampa e desnível de morros para obtenção das áreas suscetíveis a fluxos de detritos na bacia hidrográfica do Rio Taquari-Antas, RS.

Table 7. Slope intervals, slope gradient and hill slope to obtain areas susceptible to debris flow in the Taquari-Antas River basin, RS.

\begin{tabular}{c|cccccc}
\hline \multirow{2}{*}{ Suscetibilidade } & \multicolumn{2}{c}{$\begin{array}{c}\text { Declividade } \\
\text { Filtro de Média (5x5) }\end{array}$} & \multicolumn{2}{c}{$\begin{array}{c}\text { Desnível de Rampa } \\
\text { Píxel x Drenagem }\end{array}$} & \multicolumn{2}{c}{$\begin{array}{c}\text { Desnível do Morro } \\
\text { Cumeada x Drenagem }\end{array}$} \\
\cline { 2 - 7 } & LI & LS & LI & LS & LI & LS \\
\hline Baixa & $16,8 \%$ & $53,3 \%$ & $8 \mathrm{~m}$ & $674 \mathrm{~m}$ & $131 \mathrm{~m}$ & $695 \mathrm{~m}$ \\
Média & $22,2 \%$ & $51,2 \%$ & $32 \mathrm{~m}$ & $477 \mathrm{~m}$ & $158 \mathrm{~m}$ & $572 \mathrm{~m}$ \\
Alta & $29,3 \%$ & $47,1 \%$ & $73 \mathrm{~m}$ & $305 \mathrm{~m}$ & $205 \mathrm{~m}$ & $439 \mathrm{~m}$ \\
\hline
\end{tabular}

Obs.: LI é o limite inferior do intervalo; LS é o limite superior do intervalo.

tes graus de suscetibilidade, é necessário extrair as diferenças entre os três mapas. Assim, das áreas de média suscetibilidade são excluídos todos os píxeis que já apresentam alta suscetibilidade. E, por fim, das áreas de baixa suscetibilidade a fluxos de detritos são excluídos todos os píxeis que já apresentam média ou alta suscetibilidade.

As figuras 8, 9 e 10 espacializam as três variáveis escolhidas para a identificação das áreas suscetíveis, respectivamente, os mapas de declividades com filtro de média $(5 \times 5)$, de desnível de rampa e de desnível das unidades de morro. As áreas com maiores percentuais de declividades (Fig. 8) estão localizadas junto aos vales dos rios das Antas, São Marcos, da Prata, Carreiro, Guaporé, Forqueta e Fão. Trata-se de vales com rios extremamente encaixados, cujas planícies e terraços fluviais são pequenos ou inexistentes, os quais representam a Unidade Geomorfológica da Serra Geral.

As declividades médias superam o valor de $50 \%$. Observa-se que as rampas com maiores desníveis estão localizadas, em geral, no vale do Rio das Antas, na porção central da bacia, com desníveis de rampa superiores a $400 \mathrm{~m}$ (Fig. 9). Já com base na figura 10 , os morros com maiores desníveis altimétricos estão localizadas no centro-oeste da bacia, principalmente ao longo dos rios das Antas (entre os rios Lajeado Grande e Carreiro), da Prata, Guaporé, Fão, Forqueta e Taquari (entre os rios Carreiro e Forqueta), com desníveis superio- res a $500 \mathrm{~m}$.

No mapa síntese de áreas suscetíveis a fluxos de detritos da bacia do Rio Taquari-Antas (Fig. 11), fica clara a localização preferencial ao longo das linhas de escarpa erosiva que marcam o limite entre a Serra Geral e os compartimentos geomorfológicos adjacentes (Patamares Baixos da Serra Geral e Campos Gerais). A linha de escarpa erosiva está localizada em maior parte junto das vertentes referentes aos vales dos rios das Antas, da Prata, São Marcos, Carreiro, Guaporé, Forqueta, Fão e Taquari (entre os rios Carreiro e Forqueta).

A bacia do Rio Taquari-Antas possui uma área de $26.428 \mathrm{~km}^{2}$, aproximadamente 30,8\% $\left(8.147 \mathrm{~km}^{2}\right)$ pode ser considerada suscetível a fluxos de detritos. A área de baixa suscetibilidade corresponde a $3.068 \mathrm{~km}^{2}, 11,6 \%$ da área total; a média suscetibilidade representa $3.197 \mathrm{~km}^{2}, 12,1 \%$ da área total; e a área de alta suscetibilidade 1.882 $\mathrm{km}^{2}$, ou $7,1 \% \mathrm{da}$ área total.

Ao relacionar as áreas suscetíveis na bacia com os limites municipais, foram obtidas a área absoluta e o percentual de áreas suscetíveis em cada município (Tab. 8). Ao todo 113 municípios apresentam locais suscetíveis. Em termos absolutos, os municípios com maior área suscetível são Bom Jesus $\left(371,2 \mathrm{~km}^{2}\right)$, Jaquirana $\left(300 \mathrm{~km}^{2}\right) \mathrm{e}$ Fontoura Xavier $\left(295,8 \mathrm{~km}^{2}\right)$, concentrando aproximadamente $12 \%$ de todas as áreas suscetíveis.

Como pode-se observar na tabela 8 , consi- 


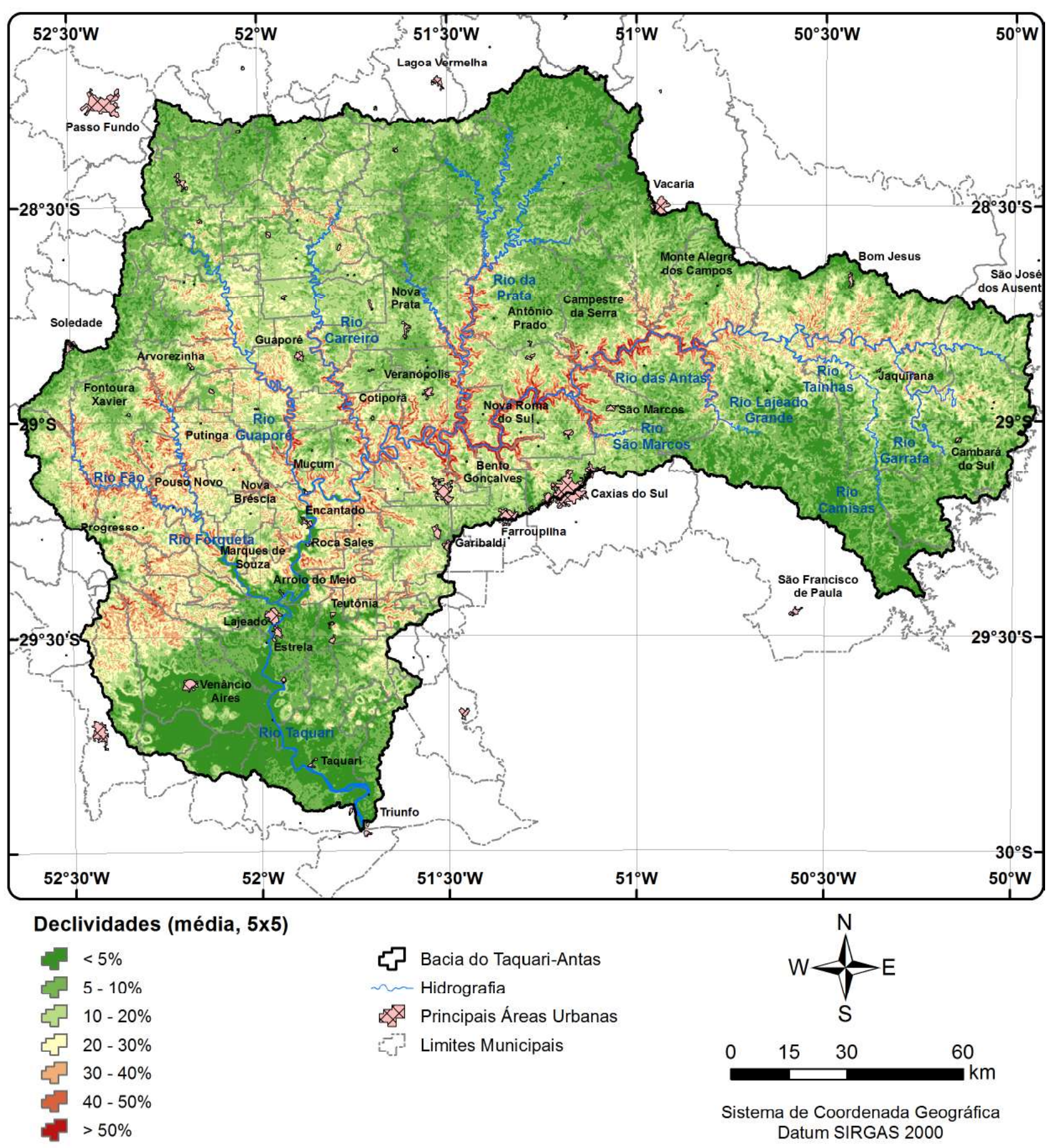

Figura 8. Declividades (média em janela $5 \times 5$ ) da bacia hidrográfica do Rio Taquari-Antas, RS.

Figure 8. Slopes (mean in $5 \times 5$ window) of the Taquari-Antas River basin, RS.

derando a relação entre a área suscetível e a área total dos municípios, destacam-se Canudos do Vale $(94,8 \%)$, Pouso Novo $(92,2 \%)$ e Sério (89\%). Ao todo, 40 municípios apresentam mais de 50\% de áreas suscetíveis em seus limites municipais, a maioria destes localizados na porção centro-oeste da bacia.

Na bacia do Rio Taquari-Antas, 102 municípios apresentam locais com alta suscetibilidade a fluxos de detritos. Em termos absolutos, se destacam Fontoura Xavier $\left(90,2 \mathrm{~km}^{2}\right)$ e Bom Jesus $(90,1$ $\mathrm{km}^{2}$ ), seguidos por Monte Alegre dos Campos, Venâncio Aires, São Francisco de Paula, Jaquirana, Progresso, Santa Cruz do Sul e Antônio Prado (Tab. 8). Juntos, os nove municípios concentram aproximadamente $31 \%$ das áreas com alta suscetibilidade. Por sua vez, considerando a relação entre as áreas de alta suscetibilidade e a área total dos municípios, destacam-se os municípios de Travesseiro $(30,1 \%)$ e Muçum (26,9\%). Ao todo, 17 municípios apresentam mais de $20 \%$ da sua área territorial com alta suscetibilidade a fluxos de de- 


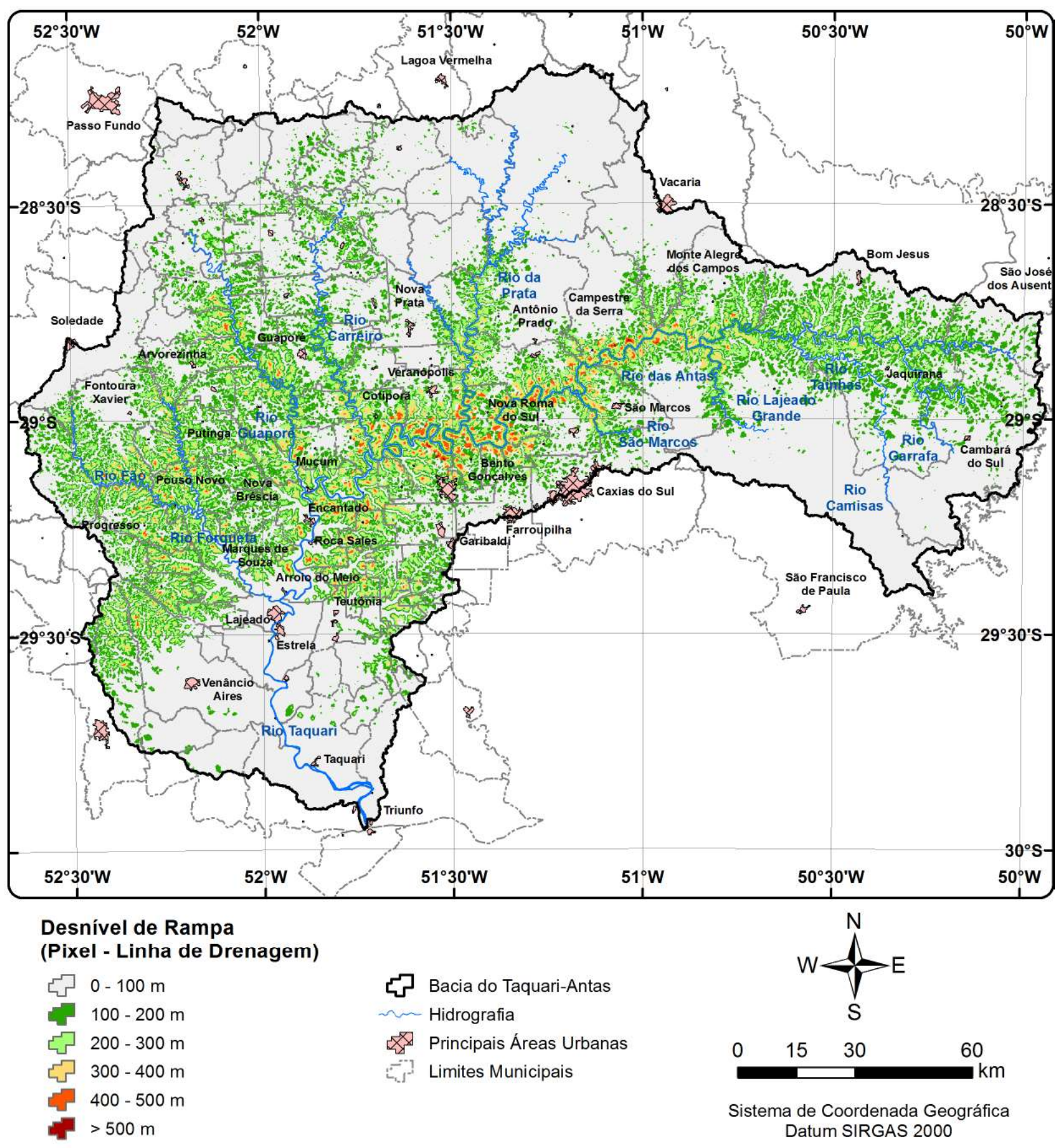

Figura 9. Mapa de desnível de rampas da bacia hidrográfica do Rio Taquari-Antas, RS.

Figure 9. Slope map of ramps of the Taquari-Antas River basin, RS.

tritos e 26 municípios apresentam entre 10 e 20\%.

Em relação às áreas suscetíveis em cada sub-bacia do Rio Taquari-Antas, observa-se que a sub-bacia do rio Forqueta se destaca como a bacia com a maior área suscetível, igual a $1.576,8 \mathrm{~km}^{2}$, equivalente a $19,4 \%$ das áreas suscetíveis em toda a bacia do Rio Taquari-Antas. Essa sub-bacia é conhecida por seus vales com rios extremamente encaixados, principalmente nos trechos dos rios Fão, Forquetinha e do alto Forqueta. Em seguida, se destacam também as sub-bacias dos rios Guaporé $\left(888,4 \mathrm{~km}^{2}\right)$, Carreiro $\left(655,5 \mathrm{~km}^{2}\right)$ e das Antas, nos trechos baixo $\left(565,9 \mathrm{~km}^{2}\right)$, médio $\left(500,1 \mathrm{~km}^{2}\right) \mathrm{e}$ alto $\left(645,1 \mathrm{~km}^{2}\right)$. Juntas, as áreas suscetíveis destas sub-bacias correspondem a $60 \%$ de todas as áreas suscetíveis da bacia do Taquari-Antas.

Considerando apenas as áreas de alta suscetibilidade em relação a cada sub-bacia, observa-se novamente que a sub-bacia do Rio Forqueta se destaca como a bacia com a maior área de alta suscetibilidade, igual a $444,1 \mathrm{~km}^{2}$, equivalente a $23,6 \%$ das áreas de alta suscetibilidade em toda a 


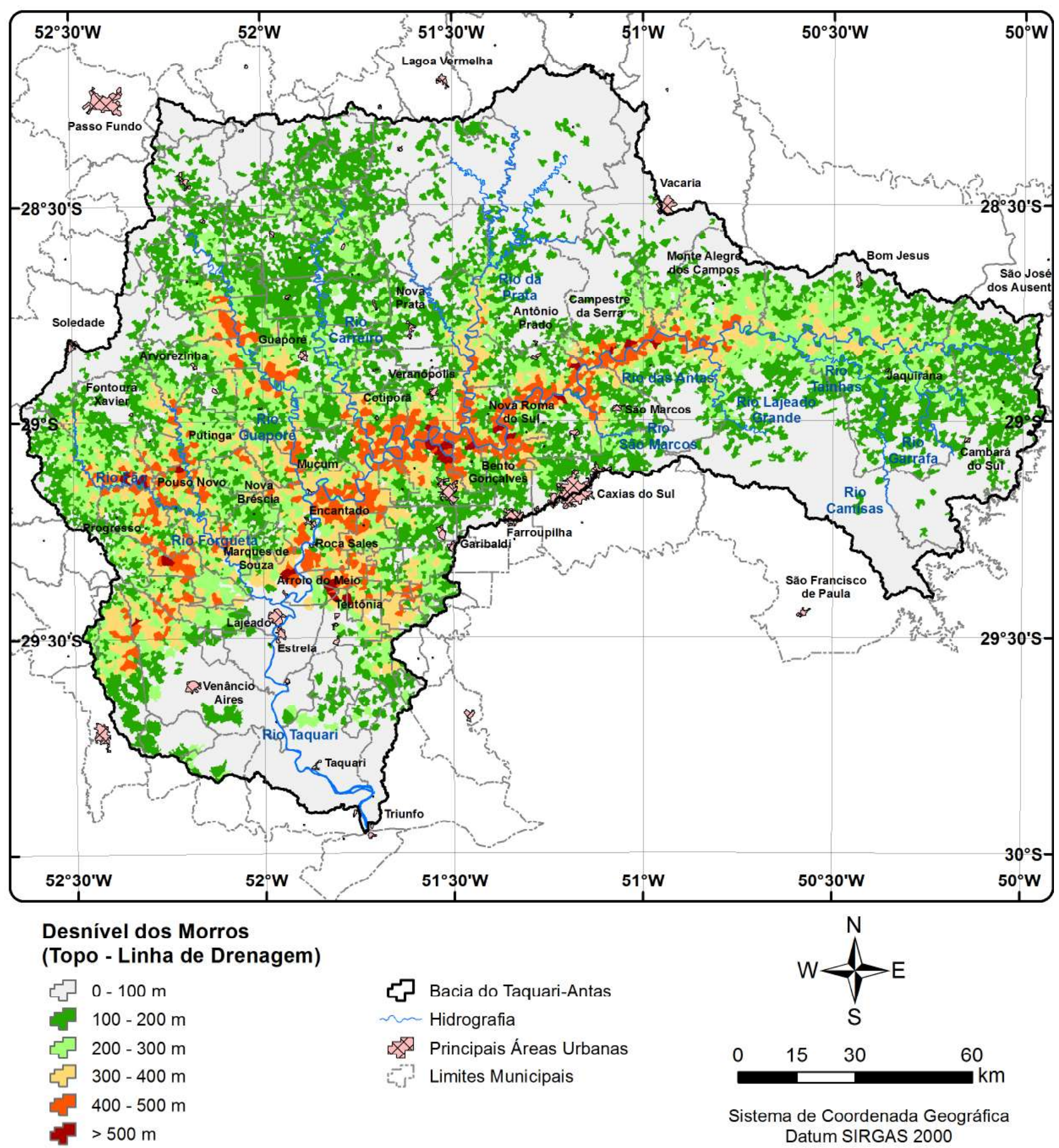

Figura 10. Mapa de desnível altimétrico dos morros da bacia do Rio Taquari-Antas, RS.

Figure 10. Altimetric gap map of the hills of the Taquari-Antas River basin, RS.

bacia do Rio Taquari-Antas. Em seguida, se destacam as sub-bacias: dos rios Guaporé $\left(176,2 \mathrm{~km}^{2}\right)$; alto rio das Antas $\left(130,1 \mathrm{~km}^{2}\right)$; médio rio das Antas $\left(127,8 \mathrm{~km}^{2}\right)$; alto rio Taquari $\left(125 \mathrm{~km}^{2}\right)$. Juntas concentram $53 \%$ das áreas de alta suscetibilidade a fluxos de detritos na bacia do Rio Taquari-Antas.

Esses resultados indicam que uma considerável porção da bacia do Rio Taquari-Antas possui algum grau de suscetibilidade, baseando-se nas semelhanças morfométricas com locais onde ocorreram deslizamentos seguidos de fluxos de detritos, como nos vales dos rios Fão e Forqueta, em janeiro de 2010, responsável pela maior enxurrada já enfrentada nos municípios de Marques de Souza e Travesseiro. De acordo com o estudo apresentado em Oliveira et al. (2017), nesse evento extremo, as centenas de deslizamentos ocorreram quase que simultaneamente, e resultaram em grande acúmulo de detritos no fundo dos vales, provocando a formação de barreiras naturais no leito dos rios. Algumas das áreas em que isso ocorreu estão localizadas junto ao Arroio Tereza e o Rio Fão (Fig. 11), 

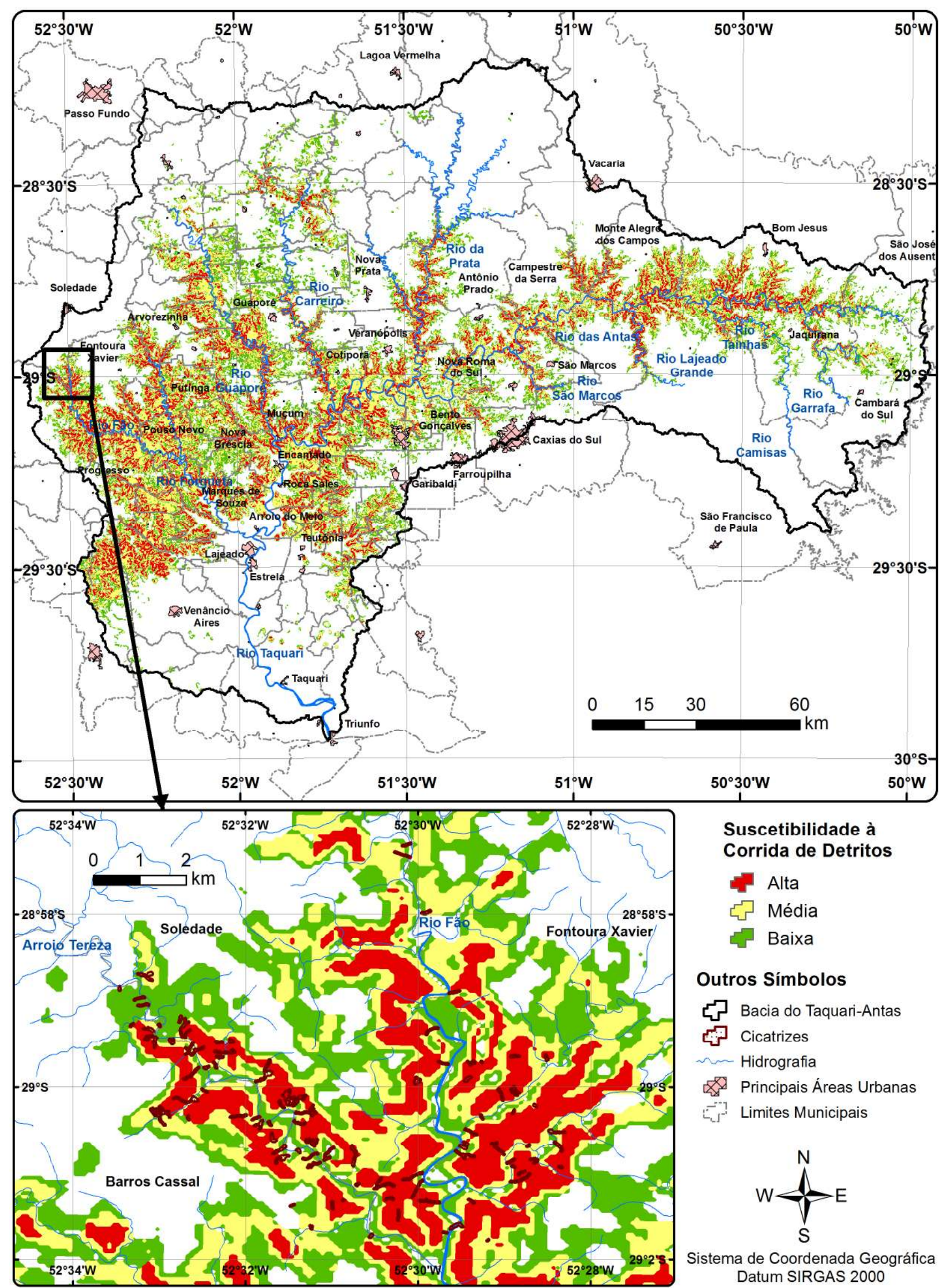

Suscetibilidade à

Corrida de Detritos

Alta
Média
Baixa

Outros Símbolos

드 Bacia do Taquari-Antas

Cicatrizes

n Hidrografia

Principais Áreas Urbanas

Limites Municipais<smiles>FC1N=C2SC2(F)N1</smiles>

Sistema de Coordenada Geográfica Datum SIRGAS 2000

Figura 11. Mapa de áreas suscetíveis a fluxos de detritos da bacia hidrográfica do Rio Taquari-Antas, RS. Figure 11. Debris flow susceptible areas map in the Taquari-Antas River basin, RS. 
Tabela 8. Relação entre os municípios e as áreas suscetíveis a fluxos de detritos na bacia hidrográfica do rio Taquari-Antas, RS. Table 8. Relationship between municipalities and the areas susceptible to debris flow in the Taquari-Antas River Basin, RS.

\begin{tabular}{ccccc}
\hline & $\begin{array}{c}\text { Área } \\
\text { Suscetível } \\
\left(\mathrm{km}^{2}\right)\end{array}$ & $\begin{array}{c}\text { Proporção de áreas } \\
\text { suscetíveis no } \\
\text { município }\end{array}$ & $\begin{array}{c}\text { Área de Alta } \\
\text { Suscetibilidade } \\
\left(\mathrm{km}^{2}\right)\end{array}$ & $\begin{array}{c}\text { Proporção de áreas de } \\
\text { alta suscetibilidade no } \\
\text { município }\end{array}$ \\
\hline Bom Jesus & 371,2 & $14,2 \%$ & 90,1 & $3,4 \%$ \\
Jaquirana & 300,0 & $33,1 \%$ & 57,3 & $6,3 \%$ \\
Fontoura Xavier & 295,8 & $50,7 \%$ & 90,2 & $15,5 \%$ \\
São Francisco de Paula & 220,8 & $6,7 \%$ & 57,6 & $1,8 \%$ \\
Caxias do Sul & 217,6 & $13,2 \%$ & 45,0 & $2,7 \%$ \\
Monte Alegre dos Campos & 217,2 & $39,5 \%$ & 66,4 & $12,1 \%$ \\
Progresso & 205,2 & $80,2 \%$ & 56,5 & $22,1 \%$ \\
Antônio Prado & 185,0 & $53,3 \%$ & 52,0 & $15,0 \%$ \\
Santa Cruz do Sul & 182,8 & $24,9 \%$ & 52,3 & $7,1 \%$ \\
Venâncio Aires & 177,2 & $22,9 \%$ & 63,7 & $8,2 \%$ \\
Canudos do Vale & 77,6 & $94,8 \%$ & 19,6 & $24,0 \%$ \\
Pouso Novo & 98,1 & $92,2 \%$ & 25,6 & $24,0 \%$ \\
Sério & 88,6 & $89,0 \%$ & 25,8 & $25,9 \%$ \\
Santa Tereza & 64,2 & $86,9 \%$ & 18,7 & $25,3 \%$ \\
Coqueiro Baixo & 95,1 & $84,7 \%$ & 19,6 & $17,5 \%$ \\
Relvado & 102,7 & $83,3 \%$ & 17,2 & $13,9 \%$ \\
Imigrante & 60,4 & $82,3 \%$ & 18,8 & $25,6 \%$ \\
Putinga & 165,5 & $80,7 \%$ & 44,5 & $21,7 \%$ \\
Travesseiro & 62,1 & $76,6 \%$ & 24,4 & $30,1 \%$ \\
Muçum & 81,4 & $73,4 \%$ & 29,8 & $26,9 \%$ \\
Poço das Antas & 46,6 & $69,0 \%$ & 17,3 & $25,6 \%$ \\
São José do Herval & 75,3 & $73,0 \%$ & 26,4 & $25,6 \%$ \\
Forquetinha & 65,8 & $70,4 \%$ & 23,1 & $24,7 \%$ \\
\hline Outros & 4690,6 & - & 939,9 & - \\
\hline Total & 8146,7 & $30,8 \%$ & 1881,7 & $7,1 \%$ \\
\hline
\end{tabular}

onde a drenagem possui um forte controle estrutural com meandros em cotovelos e ângulos retos. Nessas curvas, com relevo em forma de anfiteatro, houve um conjunto de deslizamentos que provocaram o barramento do rio pelos detritos de solos e rochas e material vegetal das árvores. Esse fenômeno já foi relatado em publicações internacionais (por exemplo, Collins \& Jibson, 2015; Dufresne et al., 2018), conhecido como Valley Blocking Landslide, existindo inclusive indícios de ter ocorrido também em Rolante, RS, em janeiro de 2017, conforme o relatório apresentado pelo Departamento de Recursos Hídricos da Secretaria do Ambiente e Desenvolvimento Sustentável do Rio Grande do Sul (DRH-SADS, 2017). As evidências de campo, as entrevistas e os relatos dos moradores, bem como a modelagem hidrológica realizada por Cas (2015) apontam para o rompimento dessas barreiras naturais, resultando na enxurrada sem precedentes na região, com aumento do nível dos rios em mais de $20 \mathrm{~m}$ em alguns pontos. Os impactos da enxurrada e a repercussão na região foi intensa, com diversas matérias publicadas sobre o episódio (ex.: 0 Globo, 2010; Zero Hora, 2010).
Além disso, cabe destacar que outras áreas urbanas poderiam ser atingidas em caso de um novo evento extremo relacionado aos movimentos de massa e, especificamente, a fluxos de detritos. Dois exemplos são os municípios de Muçum e Encantado, que se localizam no vale do Rio Taquari, na confluência do rio principal com o Rio Guaporé e o Arroio Jacaré. Essa área poderia ser atingida por detritos movimentados nos diversos cursos d'água que deságuam neste setor da bacia.

É importante destacar que na escarpa erosiva do Planalto Meridional, na Serra Geral, considerando apenas a porção localizada no Rio Grande do Sul, os deslizamentos, seguidos de corridas de detritos ocorreram de forma mais intensa em pelo menos quatro ocasiões: (i) em 25/12/2000 no vale do Rio Forromeco, nos municípios de São Vendelino e Alto Feliz (Silveira, 2008; Bressani et al., 2009); (ii) 03/03/2007 no vale do Rio Maquiné, no município de Maquiné (Monguilhott, 2008); iii) 04/01/2010 nos vales dos rios Fão e Forqueta, nos municípios de Fontoura Xavier, Barros Cassal e Soledade (Oliveira et al., 2017); iv) 05/01/2017 nos vales dos rios Rolante e Mascarada, nos muni- 
cípios de Rolante e Riozinho (DRH-SADS, 2017).

Esses eventos foram seguidos também por fortes enxurradas, poucos minutos ou horas após a ocorrência dos movimentos de massa, sendo esse o registro do evento adverso realizado pela Defesa Civil nos relatórios de avaliação de danos (AVADAN), disponíveis no banco de dados S2iD (Sistema Integrado de Informações sobre Desastres), mantido pelo Ministério da Integração Nacional (BRASIL, 2018). Isso acontece em função da localização preferencial da população, que reside nos fundos dos vales, normalmente nas seções do rio à jusante dos pontos de ruptura de movimentos de massa, pelo que os danos sejam maiores nessas áreas em função das enxurradas. Nas áreas com impacto direto dos deslizamentos e corridas de detritos, tem-se como coberturas da terra predominantes as florestas (nas áreas mais declivosas) e os usos agrossilvipastoris, apenas com pequenas comunidades associadas ao meio rural.

Assim, por meio de uma consulta ao banco de dados S2iD, pode-se constatar uma subnotificação dos casos de movimentos de massa e, particularmente, das corridas de detritos. Ao consultar também jornais de grande circulação e mídias digitais diversas, pode-se identificar uma série de eventos extremos relacionados a movimentos de massa em municípios da Bacia Hidrográfica do Rio Taquari-Antas, que foram, em sua maioria, registrados no banco de dados S2iD como enxurradas ou inundações bruscas, ainda que na descrição dos impactos tenha o relato de interrupção de rodovias, lavouras destruídas e casas atingidas por deslizamentos, quedas de blocos ou corridas de detritos. Dentre os municípios da bacia com mais relatos, matérias e/ou notificações de enxurradas e movimentos de massa se destacam: Fontoura Xavier, Barros Cassal, Santa Cruz do Sul, Bom Jesus, Sério, Venâncio Aires, Progresso e Muçum.

Em 20/07/2001, por exemplo, foram registrados dois óbitos em Barros Cassal, em função de enxurradas no Arroio Ligeiro, além de movimentos de massa e enxurradas na área rural de Venâncio Aires, com ocorrência de casas destruídas por deslizamentos (Correio do Povo, 2001). Nessa ocasião, 69 municípios em todo o RS registraram ocorrências junto à Defesa Civil, a maioria na bacia do Rio Taquari-Antas. Outro exemplo é o evento ocorrido em 27/10/2003, com registro de enxurradas e movimentos de massa na bacia, incluindo óbitos nos municípios de Forquetinha e Fontoura Xavier (Correio do Povo, 2003).

Por fim, considerando-se os resultados apresentados, destaca-se a importância de aprofundar e qualificar a extração de variáveis morfométricas, bem como os critérios e metodologias de mapeamento, baseando-se em um maior conjunto de dados digitais (solos, geologia, etc.), de relatos e registros de campo para validação e também em novos dados obtidos por sensoriamento remoto para refinar os contornos das áreas suscetíveis a fluxos de detritos.

\section{Conclusões}

Foram utilizados dados SRTM para a modelagem digital da elevação visando à delimitação da bacia hidrográfica, da hidrografia e a estimativa de índices morfométricos com objetivo de mapear e analisar as áreas suscetíveis a fluxos de detritos na bacia do Rio Taquari-Antas. 0 mapeamento foi realizado através de uma modelagem espacial com abordagem probabilística, envolvendo a elaboração de uma análise morfométrica em locais de ocorrência de deslizamentos e fluxos de detritos, inventariados por meio de imagens orbitais e expedições em campo. A metodologia permitiu atingir os resultados desejados, indicando as áreas mais suscetíveis, em graus de baixa, média e alta suscetibilidade.

No total, foram identificadas e mapeadas 193 cicatrizes de movimentos de massa. A maior parte das cicatrizes (137) se refere ao evento ocorrido em janeiro de 2010, na sub-bacia do rio Forqueta (na porção do alto Rio Fão), entre os municípios de Fontoura Xavier, Barros Cassal, Soledade e Progresso. Além destas, foram identificadas $54 \mathrm{ci}$ catrizes do evento ocorrido em dezembro de 2000, na bacia do Arroio Forromeco, entre os municípios de Alto Feliz, São Vendelino e Carlos Barbosa. As outras duas cicatrizes se referem aos municípios de Venâncio Aires e Jaquirana.

Para a modelagem das áreas suscetíveis, foram escolhidos três atributos morfométricos: declividades filtradas pela média em janela $5 \times 5$; 
desnível altimétrico da rampa; desnível altimétrico dos morros. Esses apresentaram uma tendência central bem definida, com baixa dispersão dos dados, e uma baixa correlação entre si (inferior a $0,55)$, garantindo a independência entre os três atributos. Os resultados evidenciam que a aplicação de filtros na base de declividades para extrair um comportamento geral das rupturas em função desta variável morfométrica pode ser benéfica, pois permite reduzir a variabilidade dos valores críticos para a ocorrência de fluxos de detritos.

Conclui-se, a partir dos resultados obtidos, que as áreas suscetíveis a fluxos de detritos (8.147 $\mathrm{km}^{2}$, cerca de $30 \%$ da área da bacia) estão localizadas preferencialmente ao longo das linhas de escarpa erosiva que marcam o limite entre a Serra Geral e os compartimentos geomorfológicos adjacentes (Patamares Baixos da Serra Geral e Campos Gerais). A linha de escarpa erosiva está localizada em maior parte junto das vertentes referentes aos vales dos rios das Antas, da Prata, São Marcos, Carreiro, Guaporé, Forqueta, Fão e Taquari (entre os rios Carreiro e Forqueta).

Em termos absolutos, os municípios com maior área suscetível são Bom Jesus, Jaquirana e Fontoura Xavier. Todavia, 40 municípios apresentam mais de $50 \%$ de áreas suscetíveis em seus limites municipais, a maioria destes localizados na porção centro-oeste da bacia.

Por fim, deve-se destacar a importância de aprofundar e qualificar a extração de variáveis morfométricas, bem como os critérios e metodologia de mapeamento, baseando-se em um maior conjunto de dados digitais, de relatos e registros de campo para validação e também em novos dados obtidos por sensoriamento remoto para refinar os contornos das áreas de fluxos de detritos. Estudos em escala regional são importantes para um planejamento mais eficiente dos municípios inseridos na bacia, buscando reduzir os custos inerentes à ocorrência de processos hidrometeorológicos extremos. 0 mapeamento regional pode servir de base para uma reorganização do espaço, redirecionando o crescimento das cidades e das atividades agropecuárias, em função dos desastres que ocorrem frequentemente na bacia do Taquari-Antas.
Agradecimentos. À Fundação de Amparo à Pesquisa do Estado do Rio Grande do Sul - FAPERGS pela concessão de apoio financeiro ao primeiro autor deste artigo (Edital 01/2017 - ARD, processo 17/2551-0000894-4).

\section{Referências bibliográficas}

Abe, K. \& Konagai, K. 2016. Numerical simulation for runout process of debris flow using depthaveraged material point method. Soils and Foundations, 56(5): 869-888.

Bloom, A. 1970. Superfície da Terra. São Paulo, Edgard Blücher, 184p.

BRASIL. Ministério da Integração Nacional. 2018. S2iD - Sistema Integrado de Informações sobre Desastres. Disponível em: <https://s2id.mi.gov. $\mathrm{br} /$ paginas/series/>. Acesso em: 10 mai. 2018.

Bressani, L.A., Silveira, R.M. \& Martinello, I.A. 2009. Análise de uma ruptura de talude íngreme em solo coluvionar de São Vendelino, RS. In: CONFERÊNCIA BRASILEIRA DE ESTABILIDADE DE ENCOSTAS, 5., 2009, São Paulo. Anais... São Paulo, ABMS, p. 149-157.

Brubacher, J.P., Oliveira, G.G. \& Guasselli, L.A. 2011. Suscetibilidade de enchentes a partir da análise das variáveis morfométricas na bacia hidrográfica do rio dos Sinos/RS. In: SIMPÓSIO BRASILEIRO DE SENSORIAMENTO REMOTO, 15., 2011, Curitiba. Anais... São José dos Campos, INPE, p. 1863-1870.

Bui, D.T., Tuan, T.A., Klempe, H., Pradhan, B. \& Revhaug, I. 2016. Spatial prediction models for shallow landslide hazards: a comparative assessment of the efficacy of support vector machines, artificial neural networks, kernel logistic regression, and logistic model tree. Landslides, 13(2): 361-378.

Cas, R. 2015. Estudo da influência da PCH Salto Forqueta na enchente de 4 de janeiro de 2010. Lajeado, 104p. Trabalho de Conclusão de Curso, Engenharia Civil, Centro Universitário Univates. CEPED. Centro de Estudos e Pesquisas em Engenharia e Defesa Civil. 2013. Atlas brasileiro de desastres naturais 1991 a 2012. 2a. ed., Florianópolis, CEPED UFSC, 126p.

Cheng, G., Guo, L., Zhao, T., Han, J., Li, H. \& Fang, J. 2013. Automatic landslide detection from 
remote-sensing imagery using a scene classification method based on BoVW and pLSA. International Journal of Remote Sensing, 34(1): 45-59.

Christofoletti, A. 1980. Geomorfologia. São Paulo, Edgard Blücher, 188p.

Collins, B.D. \& Jibson, R.W. 2015. Assessment of existing and potential landslide hazards resulting from the April 25, 2015 Gorkha, Nepal earthquake sequence. U.S. Geological Survey Open-File Report 2015 (1142), 50p. Disponível em: <http://dx.doi.org/10.3133/ ofr20151142>. Acesso em: 27 jun. 2018.

Conforti, M., Pascale, S., Robustelli, G. \& Sdao, F. 2014. Evaluation of prediction capability of the artificial neural networks for mapping landslide susceptibility in the Turbolo River catchment (Northern Calabria, Italy). Catena, 113: 236250.

Correio do Povo. 2001. Chuva causa mortes e bloqueia estradas. Disponível em: < http:// www.correiodopovo.com.br/Jornal/A106/ N294/HTML/>. Acesso em: 11 mai. 2018.

Correio do Povo. 2003. Sobe para cinco o número de mortos. Disponível em: < http://www. correiodopovo.com.br/Jornal/A109/N28/ HTML/>. Acesso em: 11 mai. 2018.

DRH-SADS. Departamento de Recursos Hídricos - Secretaria do Ambiente e Desenvolvimento Sustentável do Rio Grande do Sul. 2017. Diagnóstico preliminar descritivo dos eventos ocorridos no dia 05 de janeiro de 2017 entre as regiões dos municípios de São Francisco de Paula $e$ Rolante/RS. Porto Alegre, DRH-SADS, 26p.

Dufresne, A., Ostermann, M. \& Preusser, F. 2018. River-damming, late-Quaternary rockslides in the Ötz Valley region (Tyrol, Austria). Geomorphology, 310: 153-167.

Fernandes, N.F. \& Amaral, C.P. 1996. Movimentos de Massa: Uma Abordagem GeológicoGeomorfológica. In: Guerra, A.J.T. \& Guerra, S.B. (Org.). Geomorfologia e Meio Ambiente. Rio de Janeiro, Bertrand, 123-194.

Fernandes, N.F., Guimarães, R.F., Gomes, R.A.T., Vieira, B.C., Montgomery, D.R. \& Greenberg, H. 2001. Condicionantes Geomorfológicos dos Deslizamentos nas Encostas: Avaliação de Metodologias e Aplicação de Modelo de Previsão de Áreas Susceptíveis. Revista Brasileira de
Geomorfologia, 2(1): 51-71.

Ferri, G.A. \& Togni, A.C. 2012. A história da bacia hidrográfica Taquari-Antas. Lajeado, Univates, $374 \mathrm{p}$.

Guidicini, G. \& Nieble, C.M. 1984. Estabilidade de Taludes Naturais e de Escavação. São Paulo, Edgard Blücher, 194p.

He, B., Sassa, K., Nagai, O. \& Takara, K. 2014. Simulation of a rapid and long-travelling landslide using 2D-RAPID and LS-RAPID 3D models. In: Sassa K., Canuti P. \& Yin Y. (Ed.). Landslide Science for a Safer Geoenvironment. Springer, Cham, p. 479-484. Disponível em: < https://link.springer.com/ chapter/10.1007/978-3-319-04999-1_67 >. Acesso em: 14 abr. 2017.

Hearn, G.J. 1992. Terrain hazard mapping at Ok Tedi mine, Papua New Guinea. In: INTERNATIONAL SYMP. ON LANDSLIDES, 6. 1992, Christchurch. Anais... Christchurch, Balkema, p. 971-976.

Highland, L.M. \& Bobrowsky, P. 2008. The landslide handbook - A guide to understanding landslides. Reston, Virginia, U.S. Geological Survey Circular 1325, 129p.

Hollander, M. \& Wolfe, D.A. 1999. Nonparametric statistical methods. 2a. ed., New York, John Wiley \& Sons, 845p.

IPT. Instituto de Pesquisas Tecnológicas do Estado de São Paulo. 2005. Mapeamento e diagnóstico das áreas de risco associado a processos de instabilização do terreno nas encostas dos Morros de Arujá, SP. São Paulo, IPT. (Relatório 77889-205).

Jenson, S.K. \& Domingue, J.O. 1988. Extracting Topographic Structure from Digital Elevation Data for Geographic Information System Analysis. Photogrammetric Engineering and Remote Sensing, 54(11): 1593-1600.

Kanji, M.A., Cruz, P.T. \& Massad, F. 2008. Debris flow affecting the Cubatão Oil Refinery, Brazil. Landslides, 5: 71-82.

Lara, A.A., Marques, E.A.G. \& Almeida, L.C.R. 1997. Mapeamento de risco de acidentes associados a escorregamentos - Morro da Serrinha, Rio de Janeiro, Brasil. In: COBRAE, 2. 1997, Rio de Janeiro. Anais... Rio de Janeiro, ABMS, ABGE e ISSMGE, p. 837-845.

Lopes, E.S.S. 2006. Modelagem espacial dinâmica aplicada ao estudo de movimentos de massa em 
uma região da Serra do Mar Paulista, na escala de 1:10.000. Rio Claro, 282p. Tese de Doutorado, Programa de Pós-Graduação em Geociências e Meio Ambiente, Universidade Estadual Paulista. Marcelino, E.V. 2003. Mapeamento de áreas susceptíveis a escorregamentos no município de Caraguatatuba (SP) usando técnicas de sensoriamento remoto e SIG. São José dos Campos, 177p. Dissertação de Mestrado, Sensoriamento Remoto, Instituto Nacional de Pesquisas Espaciais - INPE.

Marcelino, E.V. 2008. Desastres Naturais $e$ Geotecnologias: conceitos básicos. Santa Maria, INPE/CRS, 39p. (Caderno Didático 1).

Melo, R. \& Zêzere, J. L. 2017. Avaliação da suscetibilidade à ruptura e propagação de fluxos de detritos na bacia hidrográfica do Rio Zêzere (Serra da Estrela, Portugal). Revista Brasileira de Geomorfologia, 18(1): 81-106.

Michel, G.P., Kobiyama, M. \& Goerl, R.F. 2014. Comparative analysis of SHALSTAB and SINMAP for landslide susceptibility mapping in the Cunha River basin, southern Brazil. Journal of Soils and Sediments, 14(7): 1266-1277.

Monguilhott, M. 2008. Estudo de áreas suscetíveis a movimentos de massa na rodovia $R S / 486$ Rota do Sol. Porto Alegre, 114p. Dissertação de Mestrado, Programa de Pós-Graduação em Sensoriamento Remoto, Universidade Federal do Rio Grande do Sul.

O Globo. 2010. Homem passa mais de 10 horas em cima de árvore após enchente em camping no Rio Grande do Sul. Disponível em: <https:// oglobo.globo.com/brasil/homem-passamais-de-10-horas-em-cima-de-arvore-aposenchente-em-camping-no-rio-grande-dosul-3074593 >. Acesso em: 11 mai. 2018.

Okida, R. 1996. Técnicas de sensoriamento remoto como subsídio ao zoneamento de áreas sujeitas a movimentos gravitacionais de massa e a inundações. São José dos Campos, 147p. Dissertação de Mestrado, Sensoriamento Remoto, Instituto Nacional de Pesquisas Espaciais - INPE.

Oliveira, G.G., Flores, T. \& Bresolin Junior, N.A. 2017. Análise do evento hidrometeorológico extremo ocorrido em janeiro de 2010 na bacia hidrográfica do rio Forqueta. Caderno
Pedagógico, 14(1): 181-192.

Paulino, R.B. 2013. Modelo AHP aplicado à ocorrência de deslizamentos na Região Nordeste de Santa Catarina. Curitiba, 107p. Dissertação de Mestrado, Programa de Pós-Graduação em Geografia, Setor de Ciências da Terra, Universidade Federal do Paraná.

Paz, A.R. \& Collischonn, W. 2008. Derivação de rede de drenagem a partir de dados SRTM. Revista Geográfica Acadêmica, 2(2): 84-95.

Pelizoni, B.A. 2014. Análise de Fluxos de Detritos na Região Serrana Fluminense. Rio de Janeiro, 141p. Dissertação de Mestrado, Programa de PósGraduação em Engenharia Civil, Universidade Federal do Rio de Janeiro.

Pinheiro, R.J.B., Nummer, A.V. \& Bressani, L.A. 2012. Análise da instabilidade de uma encosta localizada na área urbana em Santa Cruz do Sul, RS. Geociências, 31(2): 159-174.

Riffel, E.S. 2012. Análise e mapeamento das ocorrências de movimentos de massa na bacia hidrográfica do Rio Paranhana (RS). Porto Alegre, 115p. Dissertação de Mestrado, Programa de Pós-Graduação em Geografia, Universidade Federal do Rio Grande do Sul.

Riffel, E.S., Ruiz, L.F.C. \& Guasselli, L.A. 2016. Mapeamento de suscetibilidade a deslizamentos a partir de mineração de dados e do modelo SHALSTAB. Revista Brasileira de Cartografia, 68: 1805-1818.

Rocha, H.L. 2011. Aplicação do modelo FLO-2D para simulação de fluxos de detritos na Bacia do Rio Cunha, Rio dos Cedros/SC. Florianópolis, 123p. Dissertação de Mestrado, Programa de Pós-Graduação em Engenharia Ambiental, Universidade Federal de Santa Catarina.

Scaioni, M., Longoni, L., Melillo, V. \& Papini, M. 2014. Remote sensing for landslide investigations: An overview of recent achievements and perspectives. Remote Sensing, 6(10): 96009652.

Selby, M.J. 1985. Earth's changing surface: an introduction to geomorphology. New York, Oxford University Press, 480p.

Sestini, M.F. 1999. Variáveis geomorfológicas no estudo de deslizamentos em Caraguatatuba-SP utilizando imagens TM-Landsat e SIG. São José dos Campos, 140p. Dissertação de Mestrado, 
Sensoriamento Remoto, Instituto Nacional de Pesquisas Espaciais - INPE.

Silveira, R.M. 2008. Comportamento Geotécnico de um Solo Coluvionar de São Vendelino (RS). Porto Alegre, 301p. Tese de Doutorado, Programa de Pós-Graduação em Engenharia Civil, Escola de Engenharia, Universidade Federal do Rio Grande do Sul.

Teixeira, M.S. \& Satyamurty, P. 2004. Episódios de chuvas intensas na região sul do Brasil. Parte I: Configuração sinópticas associadas. In: CONGRESSO BRASILEIRO DE METEOROLOGIA, 13., 2004, Fortaleza. Anais... Fortaleza, SBMET, p. 1-13.

Troeh, F.R. 1965. Landform equations fitted to contour maps. American Journal of Sciences, 263: 616-627.

UNISDR. United Nations International Strategy for Disaster Reduction. 2009. Terminology on Disaster Risk Reduction. Genebra, ONU, 30p. Disponível em: <http://www.unisdr.org/ files/7817_UNISDRTerminologyEnglish.pdf>. Acesso em: 27 jun. 2018.

Valeriano, M.M. 2005. Modelo digital de variáveis morfométricas com dados SRTM para o território nacional: o projeto TOPODATA. In: SIMPÓSIO BRASILEIRO DE SENSORIAMENTO REMOTO, 12., 2005, Goiânia. Anais... Goiânia, INPE, p. 3595-3602.

Valeriano, M.M. 2008. Dados topográficos. In:
Florenzano, T.G. (Org.). Geomorfologia conceitos e tecnologias atuais. São Paulo, Oficina de Textos, p. 72-104.

Vanacôr, R.N. \& Rolim, S.B.A. 2012. Mapeamento da susceptibilidade a deslizamentos usando técnicas de estatística bivariada e sistema de informações geográficas na região nordeste do Rio Grande do Sul. Revista Brasileira de Geomorfologia, 13(1): 15-28.

Zare, M., Pourghasemi, H.R., Vafakhah, M. \& Pradhan, B. 2013. Landslide susceptibility mapping at Vaz Watershed (Iran) using an artificial neural network model: a comparison between multilayer perceptron (MLP) and radial basic function (RBF) algorithms. Arabian Journal of Geosciences, 6(8): 2873-2888.

Zero Hora. 2010. Beleza Interior: os vigias da enchente em Marques de Souza. Disponível em: <https://gauchazh.clicrbs.com.br/geral/ noticia/2011/04/beleza-interior-os-vigiasda-enchente-em-marques-de-souza-3277737. html>. Acesso em: 11 mai. 2018.

Znamensky, D. 2005. Mecanismos de formação das corridas detríticas em ambientes tropicais úmidos e a pesquisa de estruturas para o controle e manejo desses fenômenos. São Paulo, 432p. Tese de doutorado, Programa de PósGraduação em Engenharia Civil, Universidade de São Paulo. 